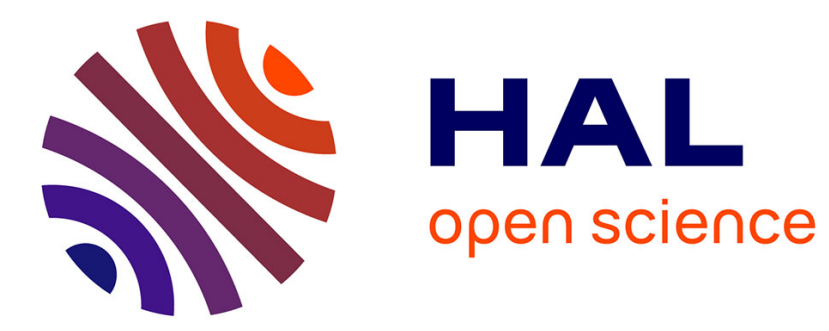

\title{
Role of astrocyte purinergic signaling in epilepsy
}

\author{
Ljiljana Nikolic, Paola Nobili, Weida Shen, Etienne Audinat
}

\section{To cite this version:}

Ljiljana Nikolic, Paola Nobili, Weida Shen, Etienne Audinat. Role of astrocyte purinergic signaling in epilepsy. Glia, 2019, 10.1002/glia.23747 . hal-02400360

\section{HAL Id: hal-02400360 \\ https://hal.science/hal-02400360}

Submitted on 20 Nov 2020

HAL is a multi-disciplinary open access archive for the deposit and dissemination of scientific research documents, whether they are published or not. The documents may come from teaching and research institutions in France or abroad, or from public or private research centers.
L'archive ouverte pluridisciplinaire HAL, est destinée au dépôt et à la diffusion de documents scientifiques de niveau recherche, publiés ou non, émanant des établissements d'enseignement et de recherche français ou étrangers, des laboratoires publics ou privés. 
3 Running title: Astrocyte purinergic signalling in epilepsy

\section{Ljiljana Nikolic $^{1}$, Paola Nobili ${ }^{2}$, Weida Shen $^{3}$, Etienne Audinat $^{4}$}

${ }^{1}$ Institute for Biological Research Siniša Stanković, University of Belgrade, Serbia

2 Neuroscience Institute CNR, Milano, Italy

${ }^{3}$ Zhejiang University City College, Hangzhou, Zhejiang, China

${ }^{4}$ Institute for Functional Genomics (IGF), University of Montpellier, CNRS, INSERM, Montpellier, France

Correspondence: Etienne Audinat

e-mail address: etienne.audinat@igf.cnrs.fr

Institut de Génomique Fonctionnelle, CNRS UMR 5203, INSERM U1191

Université de Montpellier, 141 rue de la Cardonille, 34094 Montpellier Cedex 5, France

\section{Acknowledgments}

Work in Audinat Lab is supported by grants from the Fédération pour la Recherche sur le Cerveau (FRC) and the European Commission (EC-H2020 MSCA-ITN EU-GliaPhD No. 722053). Ljiljana Nikolic is supported by Ministry of Education, Science and Technological Development of Republic of Serbia (grant no. 173027).

\section{Conflict of Interest Statement}

The authors declare no conflict of interest.

\section{Word count:}

Total: 13560 / Abstract: 109 / Introduction: 674 / Main text: 6425

\section{Number of Figures: 1}


Abstract

Epilepsy is characterized by unpredictable recurrent seizures resulting from hypersynchronous discharges from neuron assemblies. Increasing evidence indicates that aberrant astrocyte signalling to neurons plays an important role in driving the network hyperexcitability. Purinergic signalling is central in neuron-glia and glia-glia interactions and dysfunctions in communication pathways involving purinergic receptors have been reported in various CNS pathologies, such as Alzheimer disease, stroke, major depression, schizophrenia, and epilepsy. In the present review we will first discuss the mechanisms by which astrocytes influence neuronal activity. We will then review in more details recent evidence indicating that dysregulation of astrocyte purinergic signalling actively contributes to the appearance of abnormal neuronal activity in epilepsy.

Keywords: calcium signalling, cytokine, microglia, gliotransmission, inflammation,

\section{Main points}

- Purinergic signalling is a key signaling pathway in glia-glia and neuron-glia interactions.

- Purine-driven gliotransmitter release from astrocytes perturbs excitation/inhibition balance and favours the appearance of epileptiform activity. 
56 Our knowledge of astrocyte functions evolved tremendously during the last decades, adding to the classical view of supportive cells for neurons the concept that astrocytes integrate neuronal and synaptic activities and, in turn, directly influence these activities through the release of gliotransmitters. In physiological conditions, these "metabolic" and "information processing" functions usually operate on a time scale ranging from milliseconds to hours or even days, when considering brain development and hormonal cycles, and are fundamental for brain functions, including cognitive functions (Araque et al., 2014; Attwell et al., 2010; Dallérac \& Rouach, 2016; Khakh \& Sofroniew, 2015; MacDonald, Robb, Morrissey, Beall, \& Ellacott, 2019; Pellerin et al., 2007; Rusakov, Bard, Stewart, \& Henneberger, 2014; Mirko Santello, Toni, \& Volterra, 2019; Theodosis, Poulain, \& Oliet, 2008). The continuous and progressive discovery of key roles played by astrocytes in regulating brain functions has also advanced our understanding of the roles of these cells in the pathogenesis of neurological and psychiatric diseases, including Alzheimer's disease, cerebral ischemia, multiple sclerosis, Huntington's disease, major depressive disorder and epilepsy (Cresto, Pillet, Billuart, \& Rouach, 2019; Halassa, Fellin, \& Haydon, 2007; Patel, Tewari, Chaunsali, \& Sontheimer, 2019; Rossi \& Volterra, 2009; Steinhäuser, Grunnet, \& Carmignoto, 2016; Verkhratsky \& Parpura, 2016).

Epilepsy is a pathological condition affecting more than $1 \%$ of the population worldwide (Beghi, 2016; Hesdorffer et al., 2011). It is characterized by repeated and recurrent seizures altering physiological brain functioning and being responsible for the development of comorbidities such as neurological deficits. According to the International League Against Epilepsy, epilepsies should be classified as focal, generalized or combined focal and generalized, with six, non-exclusive, subgroups of etiology (structural, genetic, infectious, metabolic, immune or unknown), selected because of their potential therapeutic consequences (Scheffer et al., 2017). Many of these epilepsies result from an acute insult (e.g. stroke, trauma, infection) that triggers progressive modifications of the brain that lead to the occurrence of spontaneous recurrent seizures. Epileptogenesis corresponds to the gradual remodelling of a formerly healthy brain into a spontaneously seizing one. The latent phase separating the initial insult from the appearance of the first spontaneous seizures can last months or even years. It is followed by the chronic phase during which recurrent spontaneous seizures occur. For a long time, it has been thought that alteration in the excitation / inhibition balance, which is at the basis of seizure generation, was the 
only mechanism involved in the pathogenesis of epilepsy. Consequently, anti-epileptic drugs (AEDs) developed in the last decades mostly aimed at correcting this perturbed balance between excitatory and inhibitory neurotransmission. These pharmacological interventions can, in the best scenario, control seizures but they cannot cure the disease. Furthermore, about one third of the patients are refractory to pharmacological treatments and this ratio reaches $2 / 3$ of the patients when considering mesial temporal lobe epilepsy (MTLE), the most frequent and severe form of focal epilepsy in adults (Asadi-Pooya, Stewart, Abrams, \& Sharan, 2017). There is therefore an obvious and urgent need for the development of new AEDs. In this context, the increasing evidence that brain functions and dysfunctions rely on an integrated interplay between neurons and glial cells, and in particular astrocytes, opens new routes for the identification of promising non-neuronal targets that could lead to the development of new AEDs. Dysfunction of several astrocyte signalling pathways can contribute to hyperexcitation of neuronal networks and progression of seizures (Steinhauser and Boison, 2012; Devinsky et al., 2013; Patel et al 2019). In particular, purinergic signalling is a key signalling pathway in glia-glia and neuron-glia interactions and recent evidence indicates that this pathway contributes to the deregulation of neuronal activity in epilepsy (Engel, Alves, Sheedy, \& Henshall, 2016; Rassendren \& Audinat, 2016).

In a first section, we will briefly review the physiological functions of astrocytes that can impact on neuronal and synaptic activities, highlighting astrocyte dysfunctions that have been identified in pathological conditions and in particular in epilepsy. In the following sections, we will discuss more extensively how deregulation of ATP signalling in astrocytes can contribute to epileptogenesis and ictogenesis (i.e. the acute process generating seizures).

\section{Astrocytes: function and dysfunction in health and disease}

\subsection{Astrogliosis: an adaptive reactive phenotype}

The role of astrocytes in pathologies of the central nervous system (CNS) is widely associated with reactive phenotype developed by astrocytes in response to a rupture in CNS homeostasis. This process called astrogliosis is particularly evident in epileptic syndromes associated with hippocampal sclerosis (HS) that is characterized by a glial scar (Thom, 2014). Astrogliosis involves changes at the molecular, cellular and functional levels (Dossi, Vasile, \& Rouach, 2018). The degree of alterations observed in reactive astrocytes 
120 varies according to the type of insult inducing the reaction and to the possibility of 121 reversion of the damage (Anderson, Ao, \& Sofroniew, 2014; Sofroniew, 2009).

122 Transcriptomic analysis of reactive astrocytes has disclosed the occurrence of two broad 123 phenotypes: a pro-inflammatory phenotype A1 having detrimental effects (Lian et al., 124 2015; Liddelow et al., 2017; Zamanian et al., 2012) and an immune-suppressive 125 phenotype A2 with protective functions (Anderson et al., 2016; Liddelow \& Barres, 2017). 126 Although the specific phenotype of astrocytes in different forms of epilepsy has not yet 127 been firmly established, different studies point rather toward a deleterious A1 phenotype. 128 For example, in epilepsy models, the release of Interleukin-1beta (IL-1 $\beta$ ) and High Mobility 129 Group Box1 by astrocytes induces the activation of IL1R/TLR signalling pathways that 130 favours the induction and maintenance of seizure activity (Maroso et al., 2010; Vezzani, 131 French, Bartfai, \& Baram, 2011). However, it should be pointed out that in most cases the 132 population of astrocytes has been considered as a whole without taking into consideration 133 a possible diversity of the astrocyte reactivity (e.g. lesion vs peri-lesional area). One 134 important and still debated question is whether astrocyte reactivity is a cause or a 135 consequence of seizures. In favour of a causative role, astrocyte-specific deletion of genes 136 (tuberous sclerosis complex 1 or Beta 1 integrin) or mutation of an astrocyte-specific gene 137 (GFAP) induce astrogliosis and the occurrence of spontaneous seizures (Messing, 138 Brenner, Feany, Nedergaard, \& Goldman, 2012; Ortinski et al., 2010; Robel et al., 2015). 139 On the other hand, there were no sign of astrogliosis in non-lesional epileptogenic cortical 140 areas of patients with focal cortical dysplasia (Rossini et al., 2017). Moreover, in a guinea 141 pig model of temporal lobe epilepsy with hippocampal sclerosis (HS-MTLE; unilateral, 142 intra-hippocampal kainate), astrogliosis and cell damage were observed only in the 143 injected, and not in the contralateral, hippocampus despite the occurrence of epileptiform 144 activities in both hippocampi (Noè et al., 2019). The latter two examples suggest 145 dissociation between the occurrence of seizure and astrogliosis, as seen with the classical 146 marker GFAP. However, they do not exclude the contribution of astrocytes to the 147 functional remodelling that occurs during epileptogenesis and to the generation of 148 seizures, especially in view of the many functions of astrocytes by which they influence the 149 excitability of neuronal networks.

150 Another important aspect of astrocyte function that is affected by gliosis is their close 151 interaction with brain vasculature that they contact with their endfeet. Astrocytes in 152 physiological conditions contribute to the maintenance of blood-brain barrier (BBB) 
153 structure by increasing the expression of tight junction proteins occludin and claudin-5 and

154 by inhibiting the expression of chemokines and leukocyte adhesion molecules, which 155 would favour BBB disruption (Andreone, Lacoste, \& Gu, 2015; Zhao, Nelson, Betsholtz, \& 156 Zlokovic, 2015). Modifications of astrocyte phenotype during astrogliosis could contribute 157 to BBB impairment that occurs in epilepsy through disruption of tight-junction coupling, 158 increased expression of adhesion molecules on endothelial cells determining an increase 159 of pro-inflammatory cytokines and the extravasation of leukocytes in brain parenchyma 160 (Marchi, Granata, \& Janigro, 2014; van Vliet, Aronica, \& Gorter, 2015). Furthermore, BBB disruption in epilepsy leads to extravasation of serum albumin, which is taken up preferentially by astrocytes and activates them through transforming growth factor beta (Heinemann, Kaufer, \& Friedman, 2012). We will now review how dysfunction of several astrocyte properties can contribute to seizure and epilepsy.

\subsection{Homeostasis: keeping an eye on $\mathrm{K}^{+}$and water}

One of the most important physiological functions of astrocytes is the maintenance of ion homeostasis and, in particular, the regulation of extracellular $\mathrm{K}^{+}\left[\mathrm{K}^{+}\right]_{0}$. The accumulation of $\mathrm{K}^{+}$in the extracellular space can lead to sustained neuronal depolarization and hyperexcitability (Heinemann \& Dieter Lux, 1977; Walz, 2000). Astrocytes control [K+ $]_{0}$ by two mechanisms: $\mathrm{K}^{+}$uptake and spatial buffering. The $\mathrm{K}^{+}$uptake is mediated through $\mathrm{Na}^{+} / \mathrm{K}^{+}$pumps, $\mathrm{Na}^{+} / \mathrm{K}^{+} / \mathrm{Cl}^{-}$cotransporters and the large expression of inward-rectifier potassium (Kir) 4.1 channels and relies also on the very negative resting potential of astrocytes (D’Ambrosio, Gordon, \& Winn, 2002; Kofuji \& Newman, 2004; Ransom, Ransom, \& Sontheimer, 2000; Seifert et al., 2009). Remarkably, mice lacking Kir4.1 channels on astrocytes were impaired for $\mathrm{K}^{+}$and glutamate uptake and were more susceptible to seizures (Chever, Djukic, McCarthy, \& Amzica, 2010; Djukic, Casper, Philpot, Chin, \& McCarthy, 2007). Altered expression of astrocyte Kir4.1 channels has been reported for Alzheimer's disease (Wilcock, Vitek, \& Colton, 2009), major depressive disorder (MDD; (Medina et al., 2016) and for Huntington's disease (Tong et al., 2014). Different studies, both in humans and animal models, have highlighted a clear association between uncontrolled extracellular $\mathrm{K}^{+}$increase and epilepsy (Steinhäuser et al., 2016). In particular, measurements of extracellular $\mathrm{K}^{+}$, patch-clamp recordings of Kir currents in astrocytes, single-cell RT-PCR and immunostaining of Kir proteins revealed a reduction in Kir-mediated current and a reduction of Kir4.1 expression in surgical specimen from patients suffering from MTLE and in rodent models of MTLE (Bordey \& Sontheimer, 1998; 
186 Heinemann et al., 2000; Heuser et al., 2012; Hinterkeuser et al., 2000; Jauch, Windmüller, 187 Lehmann, Heinemann, \& Gabriel, 2002; Kivi et al., 2000; Schröder et al., 2000).

188 Control of ion homeostasis by astrocytes relies also on spatial buffering (Orkand, Nicholls, 189 \& Kuffler, 1966), which is mediated by gap junctions (GJ), channels composed of connexin 190 (Cx) 43) and Cx30 (Nagy \& Rash, 2000). These channels allow the formation of a 191 functional network between astrocytes (syncytium) and the diffusion of $\mathrm{K}^{+}$following the 192 electrochemical gradient: $\mathrm{K}^{+}$is taken up by astrocytes where neuronal activity is high, 193 diffuses through the syncytium and is released at remote sites with lower $\left[\mathrm{K}^{+}\right]_{0}$. In line with 194 the spatial buffering concept, the physiological functioning of astroglial networks should 195 have an anti-epileptic role, and indeed, a reduced threshold for generating epileptic activity was found in mice with coupling-deficient astrocytes (Pannasch et al., 2011; Wallraff et al., 2006). Furthermore, evidence suggests that alterations in astrocyte coupling could be involved in the genesis and progression of epilepsy. Using a mouse model of HS-MTLE 199 (unilateral intracortical kainate), it has been demonstrated that astrocyte coupling is 200 impaired as early as 4 hours after the induction of status epilepticus (SE), a mechanism probably related to the release of pro-inflammatory cytokines and thus suggesting that impaired coupling represents a key event in epileptogenesis (Bedner et al., 2015). Moreover, the authors showed a complete lack of GJ coupling in sclerotic hippocampi of HS-MTLE patients.

Another important function in which astrocytes are involved is the regulation of extracellular space (ECS) volume and fluid osmolarity through aquaporin 4 (AQP4), a channel mediating transmembrane water movements according to osmotic gradients and that is expressed by astrocytes mostly at perisynaptic processes and perivascular end-feet (Schwartzkroin, Baraban, \& Hochman, 1998). Regulating water flux near synapses and blood vessels may be linked to $\mathrm{K}^{+}$homeostasis (Papadopoulos \& Verkman, 2013). Mice lacking AQP4 have a mild ECS volume expansion, an elevated threshold but prolonged 212 duration for electrographic seizures induced in vivo by hippocampal electrical stimulation 213 (Binder \& Steinhäuser, 2006; Binder et al., 2006). Subsequent analysis of these mice, 214 however, indicated that they also displayed an enhanced gap junctional coupling and an 215 improved spatial $\left[\mathrm{K}^{+}\right]_{0}$ buffering (Strohschein et al., 2011). In human and in animal models 216 of MTLE, there is a loss of astrocytic perivascular AQP4, which preceeds the appearance 217 of chronic seizures (Alvestad et al., 2013; Eid et al., 2005). This suggests that perturbed 
218 polarized expression of AQP4 during epileptogenesis, together with consequences on $219\left[\mathrm{~K}^{+}\right]_{0}$ homeostasis, may be of pathophysiological relevance.

1.3. Neurotransmitter buffering: maintaining the equilibrium for glutamate, $G A B A$ and purines

A crucial role for astrocytes that can also impact on neuronal excitability is neurotransmitter buffering. Indeed, the removal of neurotransmitters, such as glutamate and GABA, from the synaptic cleft is crucial for maintaining a correct functioning of synapses and an appropriate balance between excitation and inhibition. Alterations in these buffering mechanisms could lead to neuronal hyper-excitability and excitotoxicity (Choi, 1988; Meldrum, 1994). The astrocytic buffering is mediated by neurotransmitter uptake through transporters and their metabolism through the glutamine - glutamate GABA cycle (Tore Eid, Behar, Dhaher, Bumanglag, \& Lee, 2012). Glutamate and GABA reuptake relies on specific transporters expressed by astrocytes: EAAT1 and EAAT2 (also known as GLAST and GLT1) for glutamate, and GAT1 and GAT3 for GABA. Once internalized in astrocytes, glutamate is converted into glutamine by glutamine synthetase (GS), while GABA enters the TCA cycle which produces alpha ketoglutarate, glutamate and glutamine. Glutamine produced in astrocytes is then released, up taken by neurons and used as a precursor for both glutamate and GABA synthesis.

Alterations in neurotransmitter transporters are reported in different neurological diseases, including epilepsy (Coulter \& Eid, 2012). The involvement of alterations in neurotransmitter homeostasis in epilepsy is demonstrated by an increase in extracellular glutamate levels in the sclerotic hippocampus of MTLE patients (Cavus et al., 2005, 2008). In experimental epilepsy, deletion of GLT1 in astrocytes determined an exaggerated response to subconvulsive doses of pentylenetetrazol (Tanaka et al., 1997).

Alterations in GABA extracellular levels can also contribute to hyper-excitability and epilepsy. Depending on the epileptic syndrome, both decreased extracellular GABA levels and increased GABA receptor mediated activity can be detrimental for the maintenance of excitation / inhibition balance. For example, in TLE an increase in the expression levels of GAT3 astrocytic GABA transporter, leading to a reduction of extracellular GABA levels, has been reported just before seizure onset (During \& Spencer, 1993; Lee et al., 2006). On the other hand, in absence epilepsy a dysfunction of the astrocytic GABA transporter GAT1 was responsible for the generation of non-convulsive seizures by determining an 
increase in GABA-A receptor mediated inhibition in thalamocortical neurons (Cope et al., 2009; Pirttimaki, Parri, \& Crunelli, 2013).

Reduction in GS function is involved in the pathogenesis of epilepsy by inducing extracellular glutamate accumulation, as reported in TLE patients (Eid et al., 2004; Tore Eid et al., 2016; van der Hel et al., 2005). Evidence for GS involvement in the pathogenesis of epilepsy is reported also in animal models in which blocking of GS function with the inhibitor methionine sulfoximine was able to induce recurrent seizures, neuronal loss and hippocampal atrophy (Eid et al., 2008; Wang, Zaveri, Lee, \& Eid, 2009). Considering that glutamine is fundamental also for GABA synthesis in interneurons, GS dysfunction could be related also to impaired inhibitory transmission, as shown in an experimental model of TLE in which the downregulation of GS in astrocytes was responsible for a compromised synaptic inhibitory transmission (Ortinski et al., 2010).

Another important astrocytic enzyme involved in the balance between excitation and inhibition is adenosine kinase (ADK). By phosphorylating adenosine to adenosinemonophosphate (AMP) it exerts a key role in regulating extracellular levels of adenosine (Etherington et al., 2009; Studer et al., 2006). Since adenosine is known to dampen neuronal activity, its release exerts anti-convulsant effects (Cunha, 2016; Lado \& Moshé, 2008). Astrogliosis occurring in epilepsy is known to be associated with increased levels of ADK both in humans and in experimental models (Boison, 2016). The increase in ADK and the consequent reduction of extracellular adenosine levels are responsible for reducing seizure threshold (Boison, 2016).

Altogether these data clearly highlight how crucial is neurotransmitter buffering in order to maintain a functional synaptic activity and avoid the generation of a seizure-prone context.

\subsection{Gliotransmission: sensing and modulating the surrounding environment}

The concept of the "tripartite synapse" emerged from experiments demonstrating that astrocytes are able to sense neurotransmitters released by presynaptic neurons into the synaptic cleft but also can release gliotransmitters that regulate neuronal and synaptic activities (Auld \& Robitaille, 2003; Perea, Navarrete, \& Araque, 2009).

Several classical neurotransmitters have been also identified as gliotransmitters, among which glutamate, D-serine, ATP, adenosine and GABA have been the most studied (Angulo, Le Meur, Kozlov, Charpak, \& Audinat, 2008; Araque et al., 2014; Harada, Kamiya, \& Tsuboi, 2016; Papouin, Dunphy, Tolman, Foley, \& Haydon, 2017; Petrelli \& 
282 Bezzi, 2016). An increase in intracellular $\mathrm{Ca}^{2+}$ is often crucial for the release of 283 gliotransmitters (Araque et al., 2014; Bazargani \& Attwell, 2016; Khakh \& Sofroniew, 2015; 284 Rusakov et al., 2014; Volterra, Liaudet, \& Savtchouk, 2014) that can be mediated through 285 exocytotic or non-exocytotic pathways (Hamilton \& Attwell, 2010; A. Verkhratsky, Matteoli, 286 Parpura, Mothet, \& Zorec, 2016) but gliotransmitters can be released also through $\mathrm{Ca}^{2+}$ 287 independent mechanisms involving connnexin hemichannels or pannexin channels 288 (Abudara, Retamal, Del Rio, \& Orellana, 2018), plasma membrane ion channels like P2X7 289 receptors, exchangers such as the cysteine-glutamate antiporter, or reversal of 290 neurotransmitter transporters (Malarkey \& Parpura, 2008). It should be noted, however, 291 that the existence, the possible mechanisms of gliotransmission and the functional 292 consequences of the release of gliotransmiitters are still matters of debates and 293 controversies and that in vivo studies on gliotransmission are still sparse. These issues 294 have been discussed recently in several reviews (Araque et al., 2014; Bazargani \& Attwell, 295 2016; Dallérac, Zapata, \& Rouach, 2018; Fiacco \& McCarthy, 2018; Khakh \& Sofroniew, 296 2015; Panatier \& Robitaille, 2016; Papouin, Dunphy, Tolman, Foley, et al., 2017; Rusakov 297 et al., 2014; Savtchouk \& Volterra, 2018). We will therefore only summarize here findings 298 on hippocampal gliotransmitters other than ATP that are relevant in the context of 299 epilepsy.

300 Following the pioneer work of Parri et al (Parri, Gould, \& Crunelli, 2001) in the thalamus, 301 we and others showed that astrocytes in acute slices of the hippocampus release 302 glutamate that induces slow inward currents (SICs) in CA1 pyramidal cells due to the 303 activation of extrasynaptic NMDA receptors (Angulo, Kozlov, Charpak, \& Audinat, 2004; 304 Fellin et al., 2004; G Perea \& Araque, 2005). SICs generated by a single astrocyte have 305 the capacity to synchronize a small ensemble of neurons whose soma or dendrites are 306 within the morphological domain of this astrocyte. It was later on proposed that this form of 307 gliotransmission could be at the origin of hypersynchronous excitation of neurons in 308 models of epilepsy (Kang, Xu, Xu, Nedergaard, \& Kang, 2005; Tian et al., 2005). However, 309 although $\mathrm{Ca}^{2+}$ signalling in astrocytes and $\mathrm{SICs}$ frequency are enhanced during ictal 310 events triggered in acute hippocampal slices, blocking action potentials with tetrodoxin 311 blocks ictal events but not SICs whereas blocking NMDA receptors blocks SICs but not 312 ictal events (Fellin, Gomez-Gonzalo, Gobbo, Carmignoto, \& Haydon, 2006). Yet, astrocyte 313 glutamate also contribute to set the extracellular concentration of ambient glutamate that 314 tonically activate NMDA receptors of CA1 neurons (Cavelier \& Attwell, 2005; Jabaudon et 
315 al., 1999; Le Meur, Galante, Angulo, \& Audinat, 2007) and regulate synaptic glutamate release through the activation of presynaptic metabotropic glutamate receptors or NMDA receptors in CA1 and in the dentate gyrus, respectively (Jourdain et al., 2007; Gertrudis Perea \& Araque, 2007). In the context of epilepsy, in vitro models of seizure showed that an excitatory loop involving astrocyte $\mathrm{Ca}^{2+}$ signalling, glutamate and ATP signalling lowers seizure threshold for neurons (Gomez-Gonzalo et al., 2010). Moreover, increased astrocyte $\mathrm{Ca}^{2+}$ signalling and glutamate release contribute to neuronal cell death in the neocortex in vivo after a pilocarpine induced SE (Ding et al., 2007).

Finally, it should be noted also that astrocyte $\mathrm{Ca}^{2+}$ signalling is modulated by inhibitory interneurons through GABA signalling and the activation of astrocyte GABA-B receptors and GAT-3 transporters (Mariotti, Losi, Sessolo, Marcon, \& Carmignoto, 2016; Matos et al., 2018; Mederos et al., 2019) but also through the release of somatostatin by specific interneurons (Mariotti et al., 2018). This interneuron-induced astrocyte $\mathrm{Ca}^{2+}$ signalling differentially modulates inhibitory synaptic transmission originating from different types of interneurons (Matos et al., 2018; Mederos \& Perea, 2019). Knowing the importance of neuronal inhibitory networks in different forms of epilepsy, such as temporal lobe or focal cortical epilepsies (Trevelyan, Muldoon, Merricks, Racca, \& Staley, 2015) changes in the activity or survival of inhibitory interneurons can lead to impaired astrocyte signalling that may be relevant in the context of these epilepsies.

\section{Astrocyte release of ATP (mechanisms of release)}

ATP plays an important role in physiological and pathological conditions, via activating various receptors on glia and neurons (Illes \& Verkhratsky, 2016)(Fig. 1). Under physiological conditions, the concentration of ATP in extracellular space is very low. However, it can dramatically increase under pathological conditions such as trauma, ischemia/hypoxia, inflammation or excessive neuronal activity (Engel et al., 2016; Franke, Verkhratsky, Burnstock, \& Illes, 2012; Rassendren \& Audinat, 2016; Rodrigues, Tome, \& Cunha, 2015). The sustained increase of extracellular ATP concentration under pathological conditions indicates that mechanisms regulating ATP release exist.

As for other gliotransmitters (see section 1.4), a variety of molecular mechanisms of ATP release from astrocytes have been suggested, including calcium-dependent exocytosis 
347 (Araque et al., 2014; Engel et al., 2016; Hamilton \& Attwell, 2010; Harada et al., 2016; 348 Rassendren \& Audinat, 2016; Xiong, Sun, Teng, Jin, \& Zhou, 2018). Regarding vesicular release, ATP can be packaged into vesicles and co-released with other transmitters (Zimmermann, 1994). A vesicular nucleotide transporter (VNUT) concentrating ATP into vesicles has been identified (Sawada et al., 2008) and is also expressed in non-neuronal cells where it localizes with vesicles of the regulatory secretary pathway (Lazarowski, 2012). Moreover, VNUT and fluorescent ATP co-labelled lysosomes in astrocytes have been observed and several groups have shown that astrocytes release ATP by lysosome exocytosis (Oya et al., 2013; Verderio et al., 2012; Zhang et al., 2007). Verderio and coworkers further identified that vesicle-associated membrane protein-7 (VAMP7), which is insensitive to the tetanus toxin, mediated lysosome exocytosis and contributed to ATP release from astrocytes (Verderio et al., 2012). Different functions of astrocyte vesicular release of ATP have been proposed. In cultured astrocytes, ATP vesicular release is the predominant cause of intercellular calcium waves (Bowser \& Khakh, 2007). In vivo, brainstem astrocytes were shown to control breathing through a $\mathrm{pH}$-dependent vesicular release of ATP (Gourine et al., 2010; Kasymov et al., 2013). Moreover, the use of transgenic mice expressing a dominant-negative cytoplasmic SNARE domain of the synaptobrevin-2 protein specifically in astrocytes (dnSNARE mice) provided evidence indicating that ATP vesicular release from astrocytes regulates synaptic strength and plasticity in the hippocampus (Pascual et al., 2005), sleep homeostasis in the hypothalamus (Halassa et al., 2009), inhibition and induction of long-term potentiation in the neocortex (Lalo et al., 2014; Rasooli-Nejad, Palygin, Lalo, \& Pankratov, 2014). Although the specificity of the astrocyte expression of the transgene in these mice has Additional mechanisms contributing to the release of ATP from astrocytes corresponds to the so-called conductive pathways allowing direct exchange between the cytoplasmic compartment and the extracellular space through large pores (Lazarowski, 2012; Rassendren \& Audinat, 2016). The best documented of these pathways is ATP permeation through hemichannels, either constituted by pannexins or by connexins. 
Although these two families of proteins have similar membrane topology (i.e. 4 transmembrane domains, 2 extracellular and 1 intracellular loop, along with intracellular $\mathrm{N}$ and C- terminal tails), they have no amino acid sequence homology and differ in their activation mode. Several studies have shown that pannexin-1 (PANX1) can release ATP in physiological conditions in response to the activation of different pathways, including purinergic receptor activation (Bao, Locovei, \& Dahl, 2004; Pelegrin \& Surprenant, 2006). Since PANX1 is widely expressed and can be activated at membrane potentials in the physiological range, it is considered as the major cause of ATP efflux through hemichannels. However, the positive feedback loop of ATP-induced ATP release may also constitute a danger signal under pathological conditions (Rodrigues et al., 2015) and it should be noted that the activity of PANX1 channels is much higher in acute slices (human and mice) experiencing ictal discharges than in slices without ictal discharges (Dossi, Blauwblomme, et al., 2018). Conditions leading to ATP efflux through hemiconnexins require low extracellular calcium concentration and strong depolarization, indicating that this pathway operates mostly in pathological conditions. The results obtained from pannexin- and connexin-deficient mice have led to somewhat controversial interpretations (Bedner, Steinhauser, \& Theis, 2012; Hanstein et al., 2013) but they nevertheless support the idea that hemichannels contribute to the release of ATP, particularly in pathological conditions.

Anion channels have long been suspected to mediate ATP release from astrocytes (Kimelberg, MacVicar, \& Sontheimer, 2006). In cultured astrocytes, ATP release through Maxi-anion channels may play a role in glutamate-induced release of ATP (Zhao, Gu, Liu, Zhang, \& Liu, 2017) whereas volume-regulated anion channels (VRAC) contribute to the propagation of calcium waves (Fujii, Maekawa, \& Morita, 2017) through an autocrine mechanism (Akita, Fedorovich, \& Okada, 2011). The exact contribution of astrocyte anion channels to physiological and pathological processes in vivo remains largely unknown but the recent molecular identification of several subunits constituting these channels should help resolving this issue (Han et al., 2019; Osei-Owusu, Yang, Vitery, \& Qiu, 2018). In the context of epilepsy, additional studies are required to evaluate the relative contribution of astrocytic exocytotic and conductive pathways to a rise in ATP in the extracellular space during episodes of intense neuronal activities. Interestingly, PANX1 channel activation was shown recently to promote seizure generation through ATP signalling involving P2 receptors in human cortical brain tissue and in a mouse model of MTLE (intra-hippocampal 
413 kainate) (Dossi, Blauwblomme, et al., 2018). However, both neuronal and astroglial 414 PANX1 channels were activated in these conditions and the specific role of PANX1415 dependent release of ATP from astrocytes remains to be tested.

\section{Purinergic signalling in the onset and progression of epilepsy}

418 Despite the long-lasting interest in the study of ATP as a signalling messenger the exact 419 roles of purinergic signalling in pathological conditions is far from being elucidated. Once 420 released into the extracellular space, ATP is rapidly hydrolysed to ADP and adenosine by 421 different ectonucleotidases present in the extracellular environment (Haydon \& 422 Carmignoto, 2006). Thereby, the release of ATP generates different purines that can 423 activate different types of receptors, including P2X and P2Y receptors as well as 424 adenosine receptors (Rassendren \& Audinat, 2016). The activation of these receptors may 425 have a variety of effects on the onset and progression of epilepsy and this will depend on 426 the extracellular concentrations of the different purines. It is commonly believed that these 427 concentrations increase under pathological conditions, (Franke et al., 2012; Rodrigues et 428 al., 2015) but in the context of epilepsy this has only been convincingly established for 429 adenosine (During \& Spencer, 1993; Lopatář, Dale, \& Frenguelli, 2011). However, a recent 430 in vivo study reported increased ATP concentrations after spontaneous seizures in the 431 chronic phase of the rat pilocarpine model (Doná et al., 2016). New genetically encoded 432 sensors based on the use of mutated P2 receptors should help clarifying this issue for ATP 433 and ADP.

434 Adenosine has a well-established anticonvulsant action (Boison, 2012, 2016; Cieślak, 435 Wojtczak, \& Komoszyński, 2017; Masino, Kawamura, \& Ruskin, 2014). This primarily 436 relies on the activation of adenosine A1 receptors that decrease excitatory synaptic 437 transmission and, for instance, mice lacking A1 receptors have lower threshold of seizure 438 propagation (Boison, 2012; Fedele, Li, Lan, Fredholm, \& Boison, 2006) whereas A2 and 439 A3 receptors have rather convulsive or deleterious effects (Cunha, 2016; Matute \& 440 Cavaliere, 2011). The astrocytic enzyme adenosine kinase (ADK) appears to play a key 441 role in regulating the anticonvulsant effect of adenosine. The expression of ADK is 442 upregulated during epilepsy, leading to a deficiency in adenosine concentration and thus of $\mathrm{A} 1$ receptor activation (Boison, 2016). 
444 In contrast, the role of ATP signalling in epilepsy is less well understood. There is, 445 however, a general agreement that ATP signalling contributes the pathology of epilepsy. 446 Direct application of ATP analogues in the brain evokes neuronal excitation and promotes seizure activity (Rassendren \& Audinat, 2016). There is a profound remodelling of the expression of hippocampal P2 receptors following SE in rodents (Avignone, Ulmann, Levavasseur, Rassendren, \& Audinat, 2008; Engel et al., 2016; Rassendren \& Audinat, 2016), suggesting that these receptors contribute to epileptogenesis. Analysis of the role of specific P2 receptors led to contrasting results depending on the identity of these receptors, their cellular expression but also on the type of epilepsy or on the experimental model. Many of these studies were directed toward the analysis of P2X7, P2X4 and P2Y12 receptors expressed by microglia and have been reviewed previously (Engel et al., 2016; Eyo \& Wu, 2019; Rassendren \& Audinat, 2016). Without entering in too many details, it is nevertheless worth mentioning that $\mathrm{P} 2 \mathrm{X} 4$ and $\mathrm{P} 2 \mathrm{X} 7$ have rather detrimental effects whereas P2Y12 have more protective effects on cell survival and disease progression in experimental SE or TLE. It should also be remembered that purinergic signalling is an important communication pathway between astrocytes and microglia. For instance, microglial cells sense ATP released by astrocytes (Davalos et al., 2005; Schipke, Boucsein, Ohlemeyer, Kirchhoff, \& Kettenmann, 2002) and ATP released by microglia enhances $\mathrm{Ca}^{2+}$ signalling and glutamate release by astrocytes (O. Pascual, Ben Achour, Rostaing, Triller, \& Bessis, 2012). It is therefore very likely that microglia and astrocyte purinergic signalling influence each other in pathological settings known to favour the release of ATP (see above).

The role of metabotropic P2Y1 receptors in epilepsy has been also studied. P2Y1 is expressed mostly in astrocytes, oligodendrocytes and in neurons, in particular hippocampal inhibitory interneurons (Bowser \& Khakh, 2004). A recent study based on the analysis of P2Y1 deficient mice but also on the use of selective agonists and antagonists of P2Y1 indicates that these receptors have an anticonvulsant action at the onset of SE, either triggered by systemic pilocarpine or by intra-amygdala kainate, but have proconvulsant effects once SE has been initiated and favour spontaneous seizures during the chronic phase of these models (Alves et al., 2019). Surprisingly, the same study reported an up-regulation of P2Y1 in microglia and in neurons, but no expression of these receptors in astrocytes after SE. Considering the many studies involving a role of P2Y1 in astrocytes, cell type specific knockout of P2Y1 receptors are now needed to help clarifying 
477 these complex effects (see also below). Overall these observations support the idea that 478 ATP signalling intervenes in epilepsy, but the exact mechanisms involved and their 479 influence on epileptogenesis and ictogenesis are still unclear. However, several 480 mechanisms involving ATP signalling in astrocytes have been recently updated under 481 pathological conditions and in particular in the context of epilepsy.

\section{Astrocyte ATP-mediated intercellular signalling in epilepsy}

484

485

486

ATP is an essential mediator of communication between astrocytes and between astrocytes and other types brain cells (Butt, 2011)(Fig. 1). Whether astrocyte purinemediated signalling is impaired in epilepsy is an intriguing question receiving increased attention. Genetic impairment of the vesicular ATP release from astrocytes by expressing a dominant-negative SNARE (see above and (Pascual et al., 2005)) delays the onset of recurrent seizures, decrease epileptiform activity and reduce hippocampal damage after a pilocarpine-induced SE (Clasadonte, Dong, Hines, \& Haydon, 2013). These effects probably involve the control of NMDA receptor expression that is regulated by adenosine A1 receptor activation following ATP release from astrocyte (Deng, Terunuma, Fellin, Moss, \& Haydon, 2011; Fellin et al., 2009). On the other hand, ATP release through PANX1 appears to contribute to ictal discharges in human epileptic brain tissue and in mouse models of MTLE (intra-hippocampal kainate) or SE (systemic kainate) (Dossi, Blauwblomme, et al., 2018; Santiago et al., 2011), although in these two studies the source of ATP was not specifically determined. Once released by astrocytes, ATP could have several effects. Selective activation of hippocampal astrocytes by optogenetics was shown to induce ATP release that led to the excitation of CCK-expressing interneurons, through P2Y1 receptor activation, and to the inhibition of pyramidal cells, through $A 1$ receptors (Tan et al., 2017). These effects should rather have anti-convulsive effects but it should be noted that they have been observed and studied in the presence of glutamate and GABA-A receptor antagonists, making it difficult to evaluate their consequences on the whole hippocampal network. Using a similar approach, but in absence of blockers of synaptic transmission, we observed that the initial and dominant effect of optogenetic activation of hippocampal astrocytes was an excitation of pyramidal neurons (Shen, Nikolic, Meunier, Pfrieger, \& Audinat, 2017). This excitation was the consequence of an autocrine ATP signalling in astrocytes involving P2Y1 receptors and boosting $\mathrm{Ca}^{2+}$ 
509 signalling and glutamate release from astrocytes. In CA1, this astrocyte glutamate release led to the activation of post-synaptic NMDA receptors and pre-synaptic mGluR receptors 511 on excitatory terminals. Of note, this initial excitation of pyramidal neurons was followed by an inhibition due to A1 receptor activation (Shen et al., 2017), as observed by Tan et al. 513 (2017). It is difficult to extrapolate from these observations made with optogenetic 514 activation of astrocytes in non-epileptic tissue what would be the net effect of astrocyte 515 ATP signalling in the epileptic hippocampus where concentration of purines and 516 expression of their receptors are modified (see section 3 above). However, enhanced $\mathrm{Ca}^{2+}$ 517 signalling in astrocytes, P2Y1 receptors and presynaptic mGluR receptors had been 518 already associated with epilepsy. $\mathrm{Ca}^{2+}$ signalling is enhanced in cortical astrocytes during several days after pilocarpine-induced SE and contribute to neuronal excitotoxicity (Ding et al., 2007). $\mathrm{Ca}^{2+}$ signals in hippocampal astrocytes facilitate the propagation of epileptiform activity induced by kainate in vivo (Heuser et al., 2018) and $\mathrm{Ca}^{2+}$ signalling is enhanced in astrocyte endfeet in vivo during the latent phase of a mouse model of MTLE (unilateral intra-cortical kainate; (Szokol et al., 2015)). In a rat model (rapid kindling) of MTLE, activation of $\mathrm{P} 2 \mathrm{Y} 1$ receptors is responsible for astrocyte $\mathrm{Ca}^{2+}$ hyperactivity that induces an increase in glutamate release from astrocytes and a downstream activation of neuronal mGluR5, thereby increasing release probability at the CA3-CA1 synapses (ÁlvarezFerradas et al., 2015). Blocking astrocyte $\mathrm{Ca}^{2+}$ signalling or inhibiting P2Y1 or mGluR5 receptors relieved this abnormal enhancement of synaptic strength. The same group reported subsequently that astrocyte PANX1 hemichannels are the route through which ATP is released before activating P2Y1 receptors and triggering the increased astroglial $\mathrm{Ca}^{2+}$ signalling (Wellmann, Álvarez-Ferradas, Maturana, Sáez, \& Bonansco, 2018). These observations are consistent with an enhanced autocrine ATP signalling being responsible for an increased glutamate release from astrocytes promoting neuronal excitation in the epileptic hippocampus. It is not clear yet whether this autocrine signalling pathway is involved in the purine-dependent action of astrocytes favouring ictal discharges in human epileptic brain tissue (see above and (Dossi, Blauwblomme, et al., 2018)). It should be noted, however, that in a recent study using a model of SE induced by systemic injection of kainate, targeted deletion of PANX1 from astrocytes lowers the level of ATP but potentiates seizures during SE (Scemes, Velíšek, \& Velíšková, 2019). This effect was found to be related to the lower level of adenosine consecutive to the increased level of ADK in astrocytes. 
Altogether, the majority of the above cited observations point to the conclusion that the actions of astrocyte purinergic signalling determined by the combined effects of ATP, adenosine and glutamate can displace the equilibrium between excitation and inhibition and promote appearance of epileptiform activity. It is important to note that P2Y1 regulation of astrocyte $\mathrm{Ca}^{2+}$ signalling described in the context of epilepsy has been also reported in a mouse model of Alzheimer's disease (Delekate et al., 2014; Reichenbach et al., 2018) and in a model of traumatic brain injury (Choo et al., 2013). In both cases, blocking this pathway had beneficial consequences on outcome of these models. Impaired astrocyte purinergic signalling could thus be a common signature of different CNS pathologies.

Purinergic interactions between microglia and astrocytes are likely to influence how astrocytes regulate neuronal excitability and epilepsy progression. Together with astrogliosis, reactivity of microglia is another typical feature of human and experimental epilepsies and purinergic signalling is enhanced in both cell types (Devinsky et al., 2013; Rassendren \& Audinat, 2016). In the hippocampus of naïve animals, activation of microglial TLR4 receptors rapidly induces a release of ATP that activates astrocytic P2Y1 receptors and the release of glutamate by astrocytes, which in turn activates mGluR5 receptors on presynaptic glutamatergic terminals (Pascual et al., 2012). This cascade eventually leads to an enhancement of excitability and promotes the appearance of epileptiform activities in vitro in experimental conditions where GABA receptors are blocked and external $\mathrm{Mg}^{2+}$ is low. Since microglial cells also express purinergic receptors, the release of ATP by astrocytes consecutively to the activation of P2Y1 receptors (see above) could initiate a vicious circle by recruiting further microglia. This possibility has not been specifically tested in the context of epilepsy but purine-mediated crosstalk between these glial cells has been reported in the corpus callosum (Davalos et al., 2005; Schipke et al., 2002) and also in the dentate gyrus following pilocarpine induced SE by showing that blocking microglial P2X7 receptors prevents astroglial death (Kim, Kwak, Jo, \& Kang, 2009). Interestingly, in a model of traumatic brain injury, reactive microglia induces a protective phenotype of astrocytes by down-regulating the expression of astrocytic P2Y1 receptors (Shinozaki et al., 2017).

572 Bidirectional interactions between microglia and astrocytes in epilepsy will not only set the 573 level of purinergic signalling but probably also that of microglial release of cytokines. This 574 is particularly important since cytokines are implicated in the control of glutamate release 
575 from astrocytes (see next section). Careful examination of purinergic receptors types that 576 contribute to the crosstalk between astrocytes and microglia is required to better 577 characterize paracrine glial signalling in epilepsy. Clearly more targeted genetic 578 approaches involving deletion or activation of specific type of purinergic receptor on 579 astrocytes or microglia could clarify the actual outcome of such purinergic communication 580 on the functional changes in the epileptic brain.

\section{Cytokine control of astrocyte purinergic signalling in epilepsy}

There is strong evidence that high levels of key pro-inflammatory cytokines, such as tumor necrosis factor alpha (TNF $\alpha)$ and IL-1 $\beta$, and downstream signalling that these cytokines promote, contribute to the neuronal hyper-excitability and degeneration in epilepsy (van Vliet, Aronica, Vezzani, \& Ravizza, 2018).These neuromodulatory actions of cytokines, distinct from their canonical function in the immune system, could induce seizures by acting on astrocytes in multiple ways. For instance, these cytokines released by microglia inhibit gap junctions in astrocytes in vitro (Meme et al., 2006) and in MTLE, inhibition of gap junctions by TNFa and IL-1 $\beta$ leads to the impairment of astrocytic buffering of extracellular $\mathrm{K}^{+}$(Bedner et al., 2015). Furthermore, TNFa could induce seizures through excessive astrocyte-neuron gliotransmitter mediated signalling. Clues supporting this idea can be drawn from studies showing, on the one hand, that cytokines can boost glutamate release from astrocytes (Vesce, Rossi, Brambilla, \& Volterra, 2007) and, on the other hand, that astrocytic glutamate promotes abnormal neuronal activity in epilepsy (see sections 1.4 and 4$)$.

In the context of purinergic signalling in astrocytes, TNFa is the key cytokine that can amplify astrocytic glutamate release through coupling with $\mathrm{P} 2 \mathrm{Y} 1$ receptors (Fig. 1). It was first shown that binding of TNFa to the astrocytic TNFR1 receptors is a powerful positive modulator of glutamate release from astrocytes (Bezzi et al., 2001). Later on, the same group showed that TNFa controls P2Y1R-dependent glutamate release from astrocytes (Domercq et al., 2006) and that gliotransmission driven by this pathway loses its efficacy in modulating glutamatergic synaptic activity in TNFa knockout mice (Santello, Bezzi, \& Volterra, 2011). This stimulation of astrocyte glutamate release by a cytokine was demonstrated in the dentate gyrus and leads to increase the release probability at glutamatergic synapses impinging onto granule cells through the activation of pre-synaptic 
607 NMDA receptors. It is not clear yet whether TNFa also potentiate other outcomes of astrocyte glutamate release in the hippocampus, such as the generation of SICs (Angulo et al., 2004; Fellin et al., 2004) or the mGluR-dependent potentiation of synaptic excitation in CA1 (Gertrudis Perea \& Araque, 2007).

Although P2Y1R-dependent signalling is one of the main pathways regulating astrocyteneuron interactions through the release of glutamate, it has not been considered as a specific cytokine target in the epileptic brain. However, TNFa signalling is rapidly upregulated in the hippocampus after SE (Avignone et al., 2008) and astrocytic purinergic P2Y1 signalling is highly active in models of MTLE (see above section 4). Our recent findings indicate that TNFa signalling is one pathway that increases astrocyte purinergic signalling in epilepsy. We indeed confirmed that TNFa triggers a $\mathrm{Ca}^{2+}$-dependent glutamate release from astrocytes that boosts excitatory synaptic activity in granule cells of the dentate gyrus through presynaptic NMDA receptors (see above). We further showed that this effect of TNFa can be mimicked by optogenetic activation of astrocyte and demonstrated that this action involves the autocrine activation of astrocyte P2Y1 receptors (Nikolic et al., 2018). In a mouse model of MTLE (unilateral intracortical kainate), this autocrine loop seems permanently activated at the end of the latent phase that precedes the appearance of spontaneous seizures: In the ipsilateral dentate gyrus, the frequency of mEPSCs is higher than in the control conditions, exogenous TNFa does not trigger anymore the increase of excitatory synaptic transmission and blocking P2Y1 receptors, which has no effect in control conditions, reduces excitatory synaptic activity to the level of control conditions (Nikolic et al., 2018). This signalling pathway could therefore be responsible for the lowering of seizure threshold by TNFa (lori, Frigerio, \& Vezzani, 2016) and thus be an important component of the functional remodelling (epileptogenesis) that will drive the hippocampus to spontaneous seizures.

Targeting the coupling of TNFa with astrocyte purinergic signalling may thus hold the potential to be a useful therapeutic strategy for reducing astrocytic glutamate release and normalizing synaptic activity in epilepsy. It should be kept in mind, however, that the precise mechanism of the cytokine-P2Y1 interaction in epilepsy is still unclear. A promising candidate to be considered is of course TNFR1 whose expression increased in animal model of seizures and has been reported to mediate the ictogenic effects of TNFa (lori et al., 2016). Interestingly, TNFR1 has been shown to mediate TNFa effects on astrocyte glutamate signalling in an animal model of multiple sclerosis (Habbas et al., 2015). 
640 Inhibiting the function of astrocyte TNFR1, or P2Y1, should prevent the lowering of seizure 641 threshold. Our observation that this TNFa-P2Y1 pathway is activated during the latent 642 phase, i.e. before the appearance of the first spontaneous seizures, suggests that 643 targeting this pathway could be a disease-modifying strategy through which the 644 occurrence of spontaneous seizures could be delayed or event prevented. 


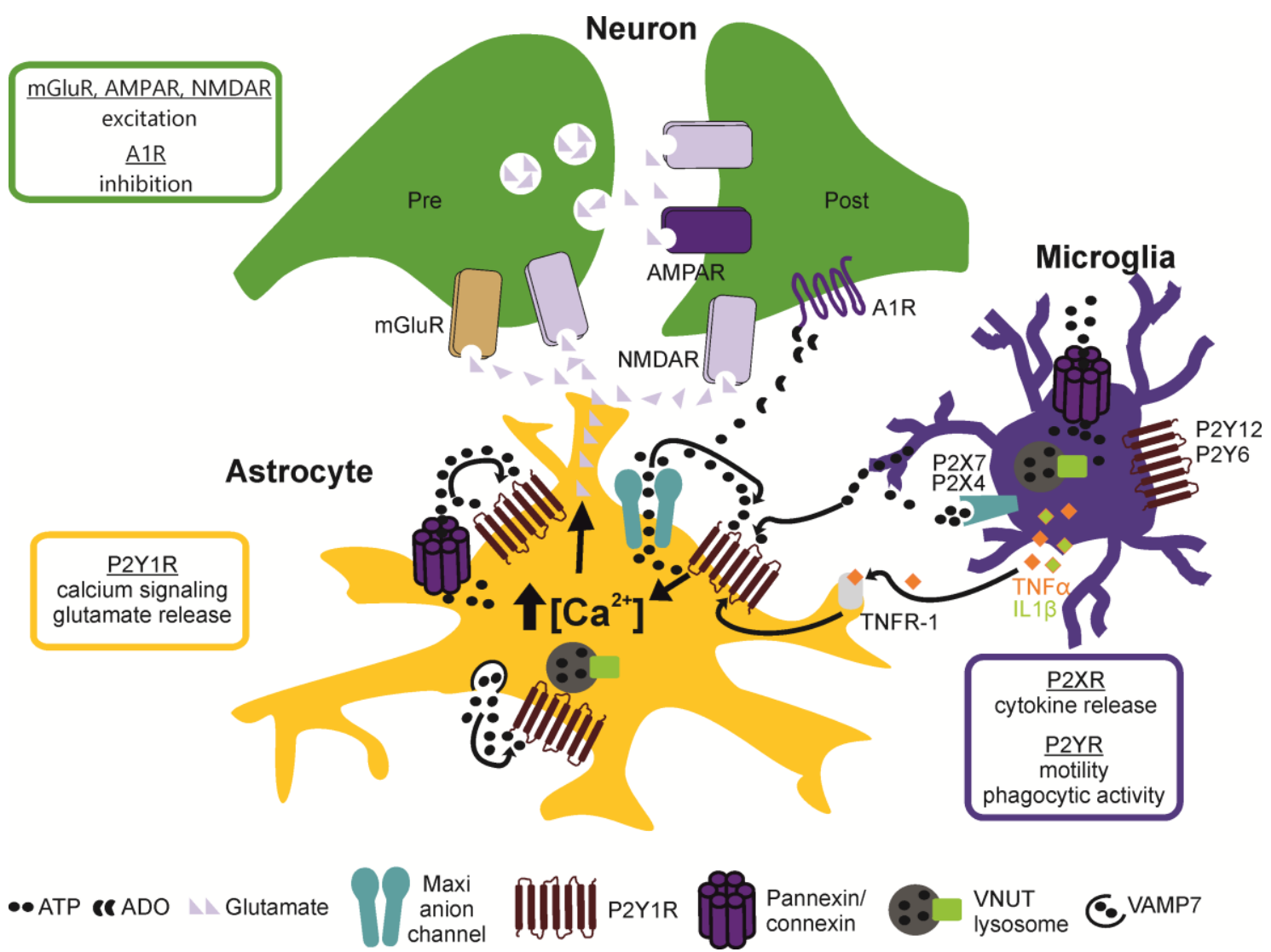

648 Figure 1: Purinergic signalling between astrocytes, neurons and microglial cells in epilepsy. The mechanisms of ATP release and the involvement of specific purinergic P2X and P2Y receptors types are depicted for astrocytes and microglia. Activation of astrocytic $\mathrm{P} 2 \mathrm{Y} 1$ receptors leads to the rise in intracellular $\mathrm{Ca}^{2+}$ that promotes astrocyte release of glutamate, which acts on pre- and post- synaptic neuronal glutamate receptors and increases excitation. ATP released from astrocytes can be converted into adenosine and promote activation of adenosine $A 1$ receptors which will favour inhibition. The cytokine TNF $\alpha$, likely released by microglia, activates the P2Y1R-dependent glutamate release from astrocytes and thus neuronal excitation. 


\section{References}

Abudara, V., Retamal, M. A., Del Rio, R., \& Orellana, J. A. (2018). Synaptic Functions of Hemichannels and Pannexons: A Double-Edged Sword. Frontiers in Molecular Neuroscience, 11. https://doi.org/10.3389/fnmol.2018.00435

Akita, T., Fedorovich, S. V, \& Okada, Y. (2011). Ca2+ nanodomain-mediated component of swelling-induced volume-sensitive outwardly rectifying anion current triggered by autocrine action of ATP in mouse astrocytes. Cellular Physiology and Biochemistry: International Journal of Experimental Cellular Physiology, Biochemistry, and Pharmacology, 28(6), 1181-1190. https://doi.org/10.1159/000335867

Álvarez-Ferradas, C., Morales, J. C., Wellmann, M., Nualart, F., Roncagliolo, M., Fuenzalida, M., \& Bonansco, C. (2015). Enhanced astroglial Ca2+ signaling increases excitatory synaptic strength in the epileptic brain. GLIA, 63(9), 1507-1521. https://doi.org/10.1002/glia.22817

Alves, M., De Diego Garcia, L., Conte, G., Jimenez-Mateos, E. M., D’Orsi, B., SanzRodriguez, A., ... Engel, T. (2019). Context-Specific Switch from Anti- to Proepileptogenic Function of the P2Y ${ }_{1}$ Receptor in Experimental Epilepsy. The Journal of Neuroscience, 39(27), 5377-5392. https://doi.org/10.1523/JNEUROSCI.0089-19.2019

Alvestad, S., Hammer, J., Hoddevik, E. H., Skare, Ø., Sonnewald, U., Amiry-Moghaddam, M., \& Ottersen, O. P. (2013). Mislocalization of AQP4 precedes chronic seizures in the kainate model of temporal lobe epilepsy. Epilepsy Research, 105(1-2), 30-41. https://doi.org/10.1016/j.eplepsyres.2013.01.006

Anderson, M. A., Ao, Y., \& Sofroniew, M. V. (2014). Heterogeneity of reactive astrocytes. Neuroscience Letters, 565, 23-29. https://doi.org/10.1016/j.neulet.2013.12.030

Anderson, M. A., Burda, J. E., Ren, Y., Ao, Y., O’Shea, T. M., Kawaguchi, R., ... Sofroniew, M. V. (2016). Astrocyte scar formation aids central nervous system axon regeneration. Nature, 532(7598), 195-200. https://doi.org/10.1038/nature17623

Andreone, B. J., Lacoste, B., \& Gu, C. (2015). Neuronal and Vascular Interactions. Annual Review of Neuroscience, 38(1), 25-46. https://doi.org/10.1146/annurev-neuro071714-033835

Angulo, M. C., Kozlov, A. S., Charpak, S., \& Audinat, E. (2004). Glutamate released from 
glial cells synchronizes neuronal activity in the hippocampus. The Journal of Neuroscience : The Official Journal of the Society for Neuroscience, 24(31), 69206927.

Angulo, M. C., Le Meur, K., Kozlov, A. S., Charpak, S., \& Audinat, E. (2008). GABA, a forgotten gliotransmitter. Progress in Neurobiology, 86(3), 297-303. https://doi.org/10.1016/j.pneurobio.2008.08.002

Araque, A., Carmignoto, G., Haydon, P. G., Oliet, S. H., Robitaille, R., \& Volterra, A. (2014). Gliotransmitters travel in time and space. Neuron, 81(4), 728-739. https://doi.org/10.1016/j.neuron.2014.02.007

Asadi-Pooya, A. A., Stewart, G. R., Abrams, D. J., \& Sharan, A. (2017). Prevalence and Incidence of Drug-Resistant Mesial Temporal Lobe Epilepsy in the United States. World Neurosurgery, 99, 662-666. https://doi.org/10.1016/j.wneu.2016.12.074

Attwell, D., Buchan, A. M., Charpak, S., Lauritzen, M., Macvicar, B. A., \& Newman, E. A. (2010). Glial and neuronal control of brain blood flow. Nature, 468(7321), 232-243. https://doi.org/10.1038/nature09613

Auld, D. S., \& Robitaille, R. (2003). Glial cells and neurotransmission: an inclusive view of synaptic function. Neuron, 40(2), 389-400. https://doi.org/10.1016/S08966273(03)00607-X

Avignone, E., Ulmann, L., Levavasseur, F., Rassendren, F., \& Audinat, E. (2008). Status epilepticus induces a particular microglial activation state characterized by enhanced purinergic signaling. The Journal of Neuroscience : The Official Journal of the Society for Neuroscience, 28(37), 9133-9144.

Bao, L., Locovei, S., \& Dahl, G. (2004). Pannexin membrane channels are mechanosensitive conduits for ATP. FEBS Letters, 572(1-3), 65-68. https://doi.org/10.1016/j.febslet.2004.07.009

Bazargani, N., \& Attwell, D. (2016). Astrocyte calcium signaling: the third wave. Nature Neuroscience, 19(2), 182-189. https://doi.org/10.1038/nn.4201

Bedner, P., Dupper, A., Huttmann, K., Muller, J., Herde, M. K., Dublin, P., ... Steinhauser, C. (2015). Astrocyte uncoupling as a cause of human temporal lobe epilepsy. Brain, 138(1460-2156 (Electronic)), 1208-1222. 
Bedner, P., Steinhauser, C., \& Theis, M. (2012). Functional redundancy and compensation among members of gap junction protein families? Biochim.Biophys.Acta, 1818(00063002 (Print)), 1971-1984.

Beghi, E. (2016). Addressing the burden of epilepsy: Many unmet needs. Pharmacological Research, 107, 79-84. https://doi.org/10.1016/j.phrs.2016.03.003

Bezzi, P., Domercq, M., Brambilla, L., Galli, R., Schols, D., De Clercq, E., ... Volterra, A. (2001). CXCR4-activated astrocyte glutamate release via TNFalpha: amplification by microglia triggers neurotoxicity. Nat.Neurosci., 4(1097-6256), 702-710.

Binder, D. K., \& Steinhäuser, C. (2006). Functional changes in astroglial cells in epilepsy. Glia, 54(5), 358-368. https://doi.org/10.1002/glia.20394

Binder, D. K., Yao, X., Zador, Z., Sick, T. J., Verkman, A. S., \& Manley, G. T. (2006). Increased seizure duration and slowed potassium kinetics in mice lacking aquaporin-4 water channels. Glia, 53(6), 631-636. https://doi.org/10.1002/glia.20318

Boison, D. (2012). Adenosine dysfunction in epilepsy. Glia, 60(8), 1234-1243. https://doi.org/10.1002/glia.22285

Boison, D. (2016). Adenosinergic signaling in epilepsy. Neuropharmacology, 104, 131139. https://doi.org/10.1016/j.neuropharm.2015.08.046

Bordey, A., \& Sontheimer, H. (1998). Properties of human glial cells associated with epileptic seizure foci. Epilepsy Research, 32(1-2), 286-303. Retrieved from http://www.ncbi.nlm.nih.gov/pubmed/9761328

Bowser, D. N., \& Khakh, B. S. (2004). ATP excites interneurons and astrocytes to increase synaptic inhibition in neuronal networks. Journal of Neuroscience, 24(1529-2401 (Electronic)), 8606-8620.

Bowser, D. N., \& Khakh, B. S. (2007). Two forms of single-vesicle astrocyte exocytosis imaged with total internal reflection fluorescence microscopy. Proc.Natl.Acad.Sci.U.S.A, 104(0027-8424 (Print)), 4212-4217.

Butt, A. M. (2011). ATP: A ubiquitous gliotransmitter integrating neuron-glial networks. Seminars in Cell \& Developmental Biology, 22(2), 205-213. https://doi.org/10.1016/j.semcdb.2011.02.023 
Cavelier, P., \& Attwell, D. (2005). Tonic release of glutamate by a DIDS-sensitive mechanism in rat hippocampal slices. J.Physiol, 564(0022-3751), 397-410.

Cavus, I., Kasoff, W. S., Cassaday, M. P., Jacob, R., Gueorguieva, R., Sherwin, R. S., ... Abi-Saab, W. M. (2005). Extracellular metabolites in the cortex and hippocampus of epileptic patients. Annals of Neurology, 57(2), 226-235. https://doi.org/10.1002/ana.20380

Cavus, I., Pan, J. W., Hetherington, H. P., Abi-Saab, W., Zaveri, H. P., Vives, K. P., ... Spencer, D. D. (2008). Decreased hippocampal volume on MRI is associated with increased extracellular glutamate in epilepsy patients. Epilepsia, 49(8), 1358-1366. https://doi.org/10.1111/j.1528-1167.2008.01603.x

Chever, O., Djukic, B., McCarthy, K. D., \& Amzica, F. (2010). Implication of Kir4.1 channel in excess potassium clearance: an in vivo study on anesthetized glial-conditional Kir4.1 knock-out mice. The Journal of Neuroscience : The Official Journal of the Society for Neuroscience, 30(47), 15769-15777. https://doi.org/10.1523/JNEUROSCI.2078-10.2010

Choi, D. W. (1988). Glutamate neurotoxicity and diseases of the nervous system. Neuron, 1(8), 623-634. Retrieved from http://www.ncbi.nlm.nih.gov/pubmed/2908446

Choo, A. M., Miller, W. J., Chen, Y.-C., Nibley, P., Patel, T. P., Goletiani, C., ... Meaney, D. F. (2013). Antagonism of purinergic signalling improves recovery from traumatic brain injury. Brain : A Journal of Neurology, 136(Pt 1), 65-80. https://doi.org/10.1093/brain/aws286

Cieślak, M., Wojtczak, A., \& Komoszyński, M. (2017). Role of the purinergic signaling in epilepsy. Pharmacological Reports : PR, 69(1), 130-138. https://doi.org/10.1016/j.pharep.2016.09.018

Clasadonte, J., Dong, J., Hines, D. J., \& Haydon, P. G. (2013). Astrocyte control of synaptic NMDA receptors contributes to the progressive development of temporal lobe epilepsy. Proceedings of the National Academy of Sciences of the United States of America, 110(43), 17540-17545. https://doi.org/10.1073/pnas.1311967110

Cope, D. W., Di, G. G., Fyson, S. J., Orban, G., Errington, A. C., Lorincz, M. L., .. Crunelli, V. (2009). Enhanced tonic GABAA inhibition in typical absence epilepsy. Nat.Med., 

15(1546-170X (Electronic)), 1392-1398.

778

779

780

781

782

783

784

785

786

787

788

789

790

791

792

793

Coulter, D. A., \& Eid, T. (2012). Astrocytic regulation of glutamate homeostasis in epilepsy. Glia, 60(8), 1215-1226. https://doi.org/10.1002/glia.22341

Cresto, N., Pillet, L.-E., Billuart, P., \& Rouach, N. (2019). Do Astrocytes Play a Role in Intellectual Disabilities? Trends in Neurosciences, 42(8), 518-527. https://doi.org/10.1016/j.tins.2019.05.011

Cunha, R. A. (2016). How does adenosine control neuronal dysfunction and neurodegeneration? Journal of Neurochemistry, 139(6), 1019-1055. https://doi.org/10.1111/jnc.13724

D’Ambrosio, R., Gordon, D. S., \& Winn, H. R. (2002). Differential role of KIR channel and $\mathrm{Na}(+) / \mathrm{K}(+)$-pump in the regulation of extracellular $\mathrm{K}(+)$ in rat hippocampus. Journal of Neurophysiology, 87(1), 87-102. https://doi.org/10.1152/jn.00240.2001

Dallérac, G., \& Rouach, N. (2016). Astrocytes as new targets to improve cognitive functions. Progress in Neurobiology, 144, 48-67. https://doi.org/10.1016/j.pneurobio.2016.01.003

Dallérac, G., Zapata, J., \& Rouach, N. (2018). Versatile control of synaptic circuits by astrocytes: where, when and how? Nature Reviews Neuroscience, 19(12), 729-743. https://doi.org/10.1038/s41583-018-0080-6

Davalos, D., Grutzendler, J., Yang, G., Kim, J. V, Zuo, Y., Jung, S., .. Gan, W. B. (2005). ATP mediates rapid microglial response to local brain injury in vivo. Nat.Neurosci., 8(1097-6256 (Print)), 752-758.

Delekate, A., Füchtemeier, M., Schumacher, T., Ulbrich, C., Foddis, M., \& Petzold, G. C. (2014). Metabotropic P2Y1 receptor signalling mediates astrocytic hyperactivity in vivo in an Alzheimer's disease mouse model. Nature Communications, 5(July 2015), 5422. https://doi.org/10.1038/ncomms6422

Deng, Q., Terunuma, M., Fellin, T., Moss, S. J., \& Haydon, P. G. (2011). Astrocytic activation of $A 1$ receptors regulates the surface expression of NMDA receptors through a Src kinase dependent pathway. Glia, 59(7), 1084-1093. https://doi.org/10.1002/glia.21181 
Devinsky, O., Vezzani, A., Najjar, S., De Lanerolle, N. C., \& Rogawski, M. A. (2013). Glia and epilepsy: excitability and inflammation. Trends Neurosci., 36(1878-108X (Electronic)), 174-184.

Ding, S., Fellin, T., Zhu, Y., Lee, S. Y., Auberson, Y. P., Meaney, D. F., ... Haydon, P. G. (2007). Enhanced astrocytic Ca2+ signals contribute to neuronal excitotoxicity after status epilepticus. J Neurosci., 27(1529-2401 (Electronic)), 10674-10684. Retrieved from http://0.0.0.12

Djukic, B., Casper, K. B., Philpot, B. D., Chin, L.-S., \& McCarthy, K. D. (2007). Conditional Knock-Out of Kir4.1 Leads to Glial Membrane Depolarization, Inhibition of Potassium and Glutamate Uptake, and Enhanced Short-Term Synaptic Potentiation. Journal of Neuroscience, 27(42), 11354-11365. https://doi.org/10.1523/JNEUROSCI.072307.2007

Domercq, M., Brambilla, L., Pilati, E., Marchaland, J., Volterra, A., \& Bezzi, P. (2006). P2Y1 receptor-evoked glutamate exocytosis from astrocytes: control by tumor necrosis factor-alpha and prostaglandins. J.Biol.Chem., 281(0021-9258 (Print)), 30684-30696.

Doná, F., Conceição, I. M., Ulrich, H., Ribeiro, E. B., Freitas, T. A., Nencioni, A. L. A., \& da Silva Fernandes, M. J. (2016). Variations of ATP and its metabolites in the hippocampus of rats subjected to pilocarpine-induced temporal lobe epilepsy. Purinergic Signalling, 12(2), 295-302. https://doi.org/10.1007/s11302-016-9504-9

Dossi, E., Blauwblomme, T., Moulard, J., Chever, O., Vasile, F., Guinard, E., ... Rouach, N. (2018). Pannexin-1 channels contribute to seizure generation in human epileptic brain tissue and in a mouse model of epilepsy. Science Translational Medicine, 10(443), eaar3796. https://doi.org/10.1126/scitranslmed.aar3796

Dossi, E., Vasile, F., \& Rouach, N. (2018). Human astrocytes in the diseased brain. Brain Research Bulletin, 136, 139-156. https://doi.org/10.1016/j.brainresbull.2017.02.001

During, M. J., \& Spencer, D. D. (1993). Extracellular hippocampal glutamate and spontaneous seizure in the conscious human brain. The Lancet, 341(8861), 16071610. https://doi.org/10.1016/0140-6736(93)90754-5

Eid, T., Ghosh, A., Wang, Y., Beckstrom, H., Zaveri, H. P., Lee, T.-S. W., ... de Lanerolle, 
N. C. (2008). Recurrent seizures and brain pathology after inhibition of glutamine synthetase in the hippocampus in rats. Brain, 131(8), 2061-2070. https://doi.org/10.1093/brain/awn133

Eid, T, Thomas, M. J., Spencer, D. D., Rundén-Pran, E., Lai, J. C. K., Malthankar, G. V, ... de Lanerolle, N. C. (2004). Loss of glutamine synthetase in the human epileptogenic hippocampus: possible mechanism for raised extracellular glutamate in mesial temporal lobe epilepsy. Lancet (London, England), 363(9402), 28-37. https://doi.org/10.1016/s0140-6736(03)15166-5

Eid, Tore, Behar, K., Dhaher, R., Bumanglag, A. V., \& Lee, T.-S. W. (2012). Roles of Glutamine Synthetase Inhibition in Epilepsy. Neurochemical Research, 37(11), 23392350. https://doi.org/10.1007/s11064-012-0766-5

Eid, Tore, Gruenbaum, S. E., Dhaher, R., Lee, T.-S. W., Zhou, Y., \& Danbolt, N. C. (2016). The Glutamate-Glutamine Cycle in Epilepsy. In Advances in neurobiology (Vol. 13, pp. 351-400). https://doi.org/10.1007/978-3-319-45096-4_14

Eid, Tore, Lee, T.-S. W., Thomas, M. J., Amiry-Moghaddam, M., Bjørnsen, L. P., Spencer, D. D., ... de Lanerolle, N. C. (2005). Loss of perivascular aquaporin 4 may underlie deficient water and $\mathrm{K}+$ homeostasis in the human epileptogenic hippocampus. Proceedings of the National Academy of Sciences of the United States of America, 102(4), 1193-1198. https://doi.org/10.1073/pnas.0409308102

Engel, T., Alves, M., Sheedy, C., \& Henshall, D. C. (2016). ATPergic signalling during seizures and epilepsy. Neuropharmacology, 104, 140-153. https://doi.org/10.1016/j.neuropharm.2015.11.001

Etherington, L.-A. V., Patterson, G. E., Meechan, L., Boison, D., Irving, A. J., Dale, N., \& Frenguelli, B. G. (2009). Astrocytic adenosine kinase regulates basal synaptic adenosine levels and seizure activity but not activity-dependent adenosine release in the hippocampus. Neuropharmacology, 56(2), 429-437. https://doi.org/10.1016/j.neuropharm.2008.09.016

Eyo, U. B., \& Wu, L.-J. (2019). Microglia: Lifelong patrolling immune cells of the brain. Progress in Neurobiology, 179, 101614. https://doi.org/10.1016/j.pneurobio.2019.04.003 
866

867

868

869

870

871

872

873

874

875

876

877

878

879

880

881

882

883

884

885

886

887

888

889

890

891

892

893

894

895

Fedele, D. E., Li, T., Lan, J. Q., Fredholm, B. B., \& Boison, D. (2006). Adenosine A1 receptors are crucial in keeping an epileptic focus localized. Experimental Neurology, 200(1), 184-190. https://doi.org/10.1016/j.expneurol.2006.02.133

Fellin, T., Gomez-Gonzalo, M., Gobbo, S., Carmignoto, G., \& Haydon, P. G. (2006). Astrocytic glutamate is not necessary for the generation of epileptiform neuronal activity in hippocampal slices. J Neurosci., 26(1529-2401 (Electronic)), 9312-9322. Retrieved from http://0.0.0.13

Fellin, T., Halassa, M. M., Terunuma, M., Succol, F., Takano, H., Frank, M., ... Haydon, P. G. (2009). Endogenous nonneuronal modulators of synaptic transmission control cortical slow oscillations in vivo. Proc.Natl.Acad.Sci.U.S.A, 106(1091-6490 (Electronic)), 15037-15042.

Fellin, T., Pascual, O., Gobbo, S., Pozzan, T., Haydon, P. G., \& Carmignoto, G. (2004). Neuronal synchrony mediated by astrocytic glutamate through activation of extrasynaptic NMDA receptors. Neuron, 43(0896-6273), 729-743.

Fiacco, T. A., \& McCarthy, K. D. (2018). Multiple Lines of Evidence Indicate That Gliotransmission Does Not Occur under Physiological Conditions. The Journal of Neuroscience, 38(1), 3-13. https://doi.org/10.1523/JNEUROSCI.0016-17.2017

Franke, H., Verkhratsky, A., Burnstock, G., \& Illes, P. (2012). Pathophysiology of astroglial purinergic signalling. Purinergic Signalling. https://doi.org/10.1007/s11302-012-9300-0

Fujii, Y., Maekawa, S., \& Morita, M. (2017). Astrocyte calcium waves propagate proximally by gap junction and distally by extracellular diffusion of ATP released from volumeregulated anion channels. Scientific Reports, 7(1), 13115. https://doi.org/10.1038/s41598-017-13243-0

Fujita, T., Chen, M. J., Li, B., Smith, N. A., Peng, W., Sun, W., .. Nedergaard, M. (2014). Neuronal Transgene Expression in Dominant-Negative SNARE Mice. Journal of Neuroscience, 34(50), 16594-16604. https://doi.org/10.1523/JNEUROSCI.258514.2014

Gomez-Gonzalo, M., Losi, G., Chiavegato, A., Zonta, M., Cammarota, M., Brondi, M., ... Carmignoto, G. (2010). An excitatory loop with astrocytes contributes to drive neurons to seizure threshold. PLoS Biology, 8(4), e1000352. 
Gourine, A. V, Kasymov, V., Marina, N., Tang, F., Figueiredo, M. F., Lane, S., ... Kasparov, S. (2010). Astrocytes control breathing through $\mathrm{pH}$-dependent release of ATP. Science, 329(1095-9203 (Electronic)), 571-575.

900

901

902

903

904

905

906

907

908

909

910

911

912

913

914

915

916

Habbas, S., Santello, M., Becker, D., Stubbe, H., Zappia, G., Liaudet, N., ... Volterra, A. (2015). Neuroinflammatory TNFalpha Impairs Memory via Astrocyte Signaling. Cell, 163(7), 1730-1741. https://doi.org/10.1016/j.cell.2015.11.023

Halassa, M. M., Fellin, T., \& Haydon, P. G. (2007). The tripartite synapse: roles for gliotransmission in health and disease. Trends in Molecular Medicine, 13(2), 54-63. https://doi.org/10.1016/j.molmed.2006.12.005

Halassa, M. M., Florian, C., Fellin, T., Munoz, J. R., Lee, S. Y., Abel, T., ... Frank, M. G. (2009). Astrocytic modulation of sleep homeostasis and cognitive consequences of sleep loss. Neuron, 61(2), 213-219. https://doi.org/10.1016/j.neuron.2008.11.024

Hamilton, N. B., \& Attwell, D. (2010). Do astrocytes really exocytose neurotransmitters? Nat.Rev.Neurosci., 11(1471-0048 (Electronic)), 227-238.

Han, Y.-E., Kwon, J., Won, J., An, H., Jang, M. W., Woo, J., .. Lee, C. J. (2019). Tweetyhomolog (Ttyh) Family Encodes the Pore-forming Subunits of the Swelling-dependent Volume-regulated Anion Channel (VRAC swell) in the Brain. Experimental Neurobiology, 28(2), 183. https://doi.org/10.5607/en.2019.28.2.183

Hanstein, R., Negoro, H., Patel, N. K., Charollais, A., Meda, P., Spray, D. C., .. Scemes, E. (2013). Promises and pitfalls of a Pannexin1 transgenic mouse line. Frontiers in Pharmacology, 4, 61. https://doi.org/10.3389/fphar.2013.00061

Harada, K., Kamiya, T., \& Tsuboi, T. (2016). Gliotransmitter Release from Astrocytes: Functional, Developmental, and Pathological Implications in the Brain. Frontiers in Neuroscience, 9. https://doi.org/10.3389/fnins.2015.00499

Haydon, P. G., \& Carmignoto, G. (2006). Astrocyte Control of Synaptic Transmission and Neurovascular Coupling. Physiological Reviews, 86(3), 1009-1031. https://doi.org/10.1152/physrev.00049.2005

Heinemann, U, Gabriel, S., Jauch, R., Schulze, K., Kivi, A., Eilers, A., ... Lehmann, T. N. 

(2000). Alterations of glial cell function in temporal lobe epilepsy. Epilepsia, 41 Suppl 6, S185-9. Retrieved from http://www.ncbi.nlm.nih.gov/pubmed/10999542

Heinemann, U, Kaufer, D., \& Friedman, A. (2012). Blood-brain barrier dysfunction, TGFbeta signaling, and astrocyte dysfunction in epilepsy. Glia, 60(1098-1136 (Electronic)), 1251-1257.

Heinemann, Uwe, \& Dieter Lux, H. (1977). Ceiling of stimulus induced rises in extracellular potassium concentration in the cerebral cortex of cat. Brain Research, 120(2), 231249. https://doi.org/10.1016/0006-8993(77)90903-9

Hesdorffer, D. C., Logroscino, G., Benn, E. K. T., Katri, N., Cascino, G., \& Hauser, W. A. (2011). Estimating risk for developing epilepsy: A population-based study in Rochester, Minnesota. Neurology, 76(1), 23-27. https://doi.org/10.1212/WNL.0b013e318204a36a

Heuser, K., Eid, T., Lauritzen, F., Thoren, A. E., Vindedal, G. F., Taubøll, E., ... Lanerolle, N. C. de. (2012). Loss of Perivascular Kir4.1 Potassium Channels in the Sclerotic Hippocampus of Patients With Mesial Temporal Lobe Epilepsy. Journal of Neuropathology \& Experimental Neurology, 71(9), 814-825. https://doi.org/10.1097/NEN.0b013e318267b5af

Heuser, K., Nome, C. G., Pettersen, K. H., Åbjørsbråten, K. S., Jensen, V., Tang, W., ... Enger, R. (2018). Ca2+ Signals in Astrocytes Facilitate Spread of Epileptiform Activity. Cerebral Cortex, 28(11), 4036-4048. https://doi.org/10.1093/cercor/bhy196

Hinterkeuser, S., Schröder, W., Hager, G., Seifert, G., Blümcke, I., Elger, C. E., ... Steinhäuser, C. (2000). Astrocytes in the hippocampus of patients with temporal lobe epilepsy display changes in potassium conductances. The European Journal of Neuroscience, 12(6), 2087-2096. Retrieved from http://www.ncbi.nlm.nih.gov/pubmed/10886348

Illes, P., \& Verkhratsky, A. (2016). Purinergic neurone-glia signalling in cognitive-related pathologies. Neuropharmacology, 104, 62-75. https://doi.org/10.1016/j.neuropharm.2015.08.005

Iori, V., Frigerio, F., \& Vezzani, A. (2016). Modulation of neuronal excitability by immune mediators in epilepsy. Current Opinion in Pharmacology, 26, 118-123. 
https://doi.org/10.1016/j.coph.2015.11.002

Jabaudon, D., Shimamoto, K., Yasuda-Kamatani, Y., Scanziani, M., Gahwiler, B. H., \& Gerber, U. (1999). Inhibition of uptake unmasks rapid extracellular turnover of glutamate of nonvesicular origin. Proc.Natl.Acad.Sci.U.S.A, 96(0027-8424), 87338738 .

Jauch, R., Windmüller, O., Lehmann, T.-N., Heinemann, U., \& Gabriel, S. (2002). Effects of barium, furosemide, ouabaine and 4,4'-diisothiocyanatostilbene-2,2'-disulfonic acid (DIDS) on ionophoretically-induced changes in extracellular potassium concentration in hippocampal slices from rats and from patients with epilepsy. Brain Research, 925(1), 18-27. https://doi.org/10.1016/S0006-8993(01)03254-1

Jourdain, P., Bergersen, L. H., Bhaukaurally, K., Bezzi, P., Santello, M., Domercq, M., ... Volterra, A. (2007). Glutamate exocytosis from astrocytes controls synaptic strength. Nat.Neurosci., 10(1097-6256 (Print)), 331-339.

Kang, N., Xu, J., Xu, Q., Nedergaard, M., \& Kang, J. (2005). Astrocytic glutamate releaseinduced transient depolarization and epileptiform discharges in hippocampal CA1 pyramidal neurons. J.Neurophysiol., 94(0022-3077 (Print)), 4121-4130.

Kasymov, V., Larina, O., Castaldo, C., Marina, N., Patrushev, M., Kasparov, S., \& Gourine, A. V. (2013). Differential Sensitivity of Brainstem versus Cortical Astrocytes to Changes in pH Reveals Functional Regional Specialization of Astroglia. Journal of Neuroscience, 33(2), 435-441. https://doi.org/10.1523/JNEUROSCI.2813-12.2013

Khakh, B. S., \& Sofroniew, M. V. (2015). Diversity of astrocyte functions and phenotypes in neural circuits. Nature Neuroscience, 18(7), 942-952. https://doi.org/10.1038/nn.4043

Kim, J.-E., Kwak, S.-E., Jo, S.-M., \& Kang, T.-C. (2009). Blockade of P2X receptor prevents astroglial death in the dentate gyrus following pilocarpine-induced status epilepticus. Neurological Research, 31(9), 982-988. https://doi.org/10.1179/174313209X389811

Kimelberg, H. K., MacVicar, B. A., \& Sontheimer, H. (2006). Anion channels in astrocytes: biophysics, pharmacology, and function. Glia, 54(0894-1491 (Print)), 747-757.

Kivi, A., Lehmann, T. N., Kovacs, R., Eilers, A., Jauch, R., Meencke, H. J., ... Gabriel, S. (2000). Effects of barium on stimulus-induced rises of [K+]o in human epileptic non- 
sclerotic and sclerotic hippocampal area CA1. Eur.J Neurosci., 12(0953-816X (Print)), 2039-2048.

Kofuji, P., \& Newman, E. A. (2004). Potassium buffering in the central nervous system. Neuroscience, 129(4), 1043-1054. https://doi.org/10.1016/j.neuroscience.2004.06.008

Lado, F. A., \& Moshé, S. L. (2008). How do seizures stop? Epilepsia, 49(10), 1651-1664. https://doi.org/10.1111/j.1528-1167.2008.01669.x

Lalo, U., Palygin, O., Rasooli-Nejad, S., Andrew, J., Haydon, P. G., \& Pankratov, Y. (2014). Exocytosis of ATP From Astrocytes Modulates Phasic and Tonic Inhibition in the Neocortex. PLoS Biology, 12(1). https://doi.org/10.1371/journal.pbio.1001747

Lazarowski, E. R. (2012). Vesicular and conductive mechanisms of nucleotide release. Purinergic Signalling, 8(3), 359-373. https://doi.org/10.1007/s11302-012-9304-9

Le Meur, K., Galante, M., Angulo, M. C. M. C., \& Audinat, E. (2007). Tonic activation of NMDA receptors by ambient glutamate of non-synaptic origin in the rat hippocampus. The Journal of Physiology, 580(Pt. 2), 373-383. https://doi.org/10.1113/jphysiol.2006.123570

Lee, T.-S., Bjørnsen, L. P., Paz, C., Kim, J. H., Spencer, S. S., Spencer, D. D., ... de Lanerolle, N. C. (2006). GAT1 and GAT3 expression are differently localized in the human epileptogenic hippocampus. Acta Neuropathologica, 111(4), 351-363. https://doi.org/10.1007/s00401-005-0017-9

Lian, H., Yang, L., Cole, A., Sun, L., Chiang, A. C.-A., Fowler, S. W., ... Zheng, H. (2015). NFKB-activated astroglial release of complement $\mathrm{C} 3$ compromises neuronal morphology and function associated with Alzheimer's disease. Neuron, 85(1), 101115. https://doi.org/10.1016/j.neuron.2014.11.018

Liddelow, S. A., \& Barres, B. A. (2017). Reactive Astrocytes: Production, Function, and Therapeutic Potential. Immunity, 46(6), 957-967. https://doi.org/10.1016/j.immuni.2017.06.006

Liddelow, S. A., Guttenplan, K. A., Clarke, L. E., Bennett, F. C., Bohlen, C. J., Schirmer, L., ... Barres, B. A. (2017). Neurotoxic reactive astrocytes are induced by activated microglia. Nature, 541(7638), 481-487. https://doi.org/10.1038/nature21029 
1015

1016

1017

1018

1019

1020

1021

1022

1023

1024

1025

1026

1027

1028

1029

1030

1031

1032

1033

1034

1035

1036

1037

1038

1039

1040

1041

1042

1043

1044

Lopatáŕ, J., Dale, N., \& Frenguelli, B. G. (2011). Minor contribution of ATP P2 receptors to electrically-evoked electrographic seizure activity in hippocampal slices: Evidence from purine biosensors and P2 receptor agonists and antagonists.

Neuropharmacology, 61(1-2), 25-34.

https://doi.org/10.1016/j.neuropharm.2011.02.011

MacDonald, A. J., Robb, J. L., Morrissey, N. A., Beall, C., \& Ellacott, K. L. J. (2019). Astrocytes in neuroendocrine systems: An overview. Journal of Neuroendocrinology, 31(5), e12726. https://doi.org/10.1111/jne.12726

Malarkey, E. B., \& Parpura, V. (2008). Mechanisms of glutamate release from astrocytes. Neurochemistry International, 52(1-2), 142-154. https://doi.org/10.1016/j.neuint.2007.06.005

Marchi, N., Granata, T., \& Janigro, D. (2014). Inflammatory pathways of seizure disorders. Trends in Neurosciences, 37(1878-108X (Electronic)), 55-65. https://doi.org/10.1016/j.tins.2013.11.002

Mariotti, L., Losi, G., Lia, A., Melone, M., Chiavegato, A., Gómez-Gonzalo, M., ... Carmignoto, G. (2018). Interneuron-specific signaling evokes distinctive somatostatinmediated responses in adult cortical astrocytes. Nature Communications, 9(1), 82. https://doi.org/10.1038/s41467-017-02642-6

Mariotti, L., Losi, G., Sessolo, M., Marcon, I., \& Carmignoto, G. (2016). The inhibitory neurotransmitter GABA evokes long-lasting $\mathrm{Ca2}+$ oscillations in cortical astrocytes. Glia, 64(3), 363-373. https://doi.org/10.1002/glia.22933

Maroso, M., Balosso, S., Ravizza, T., Liu, J., Aronica, E., Iyer, A. M., ... Vezzani, A. (2010). Toll-like receptor 4 and high-mobility group box-1 are involved in ictogenesis and can be targeted to reduce seizures. Nat.Med., 16(1546-170X (Electronic)), 413419.

Masino, S. A., Kawamura, M., \& Ruskin, D. N. (2014). Adenosine Receptors and Epilepsy. In International review of neurobiology (Vol. 119, pp. 233-255). https://doi.org/10.1016/B978-0-12-801022-8.00011-8

Matos, M., Bosson, A., Riebe, I., Reynell, C., Vallée, J., Laplante, I., ... Lacaille, J.-C. (2018). Astrocytes detect and upregulate transmission at inhibitory synapses of 
somatostatin interneurons onto pyramidal cells. Nature Communications, 9(1), 4254. https://doi.org/10.1038/s41467-018-06731-y

Matute, C., \& Cavaliere, F. (2011). Neuroglial interactions mediated by purinergic signalling in the pathophysiology of CNS disorders. Seminars in Cell \& Developmental Biology, 22(2), 252-259. https://doi.org/10.1016/j.semcdb.2011.02.011

Mederos, S., Hernández-Vivanco, A., Ramírez-Franco, J., Martín-Fernández, M., Navarrete, M., Yang, A., ... Perea, G. (2019). Melanopsin for precise optogenetic activation of astrocyte-neuron networks. Glia, 67(5), 915-934. https://doi.org/10.1002/glia.23580

Mederos, S., \& Perea, G. (2019). GABAergic-astrocyte signaling: A refinement of inhibitory brain networks. Glia, glia.23644. https://doi.org/10.1002/glia.23644

Medina, A., Watson, S. J., Bunney, W., Myers, R. M., Schatzberg, A., Barchas, J., ... Thompson, R. C. (2016). Evidence for alterations of the glial syncytial function in major depressive disorder. Journal of Psychiatric Research, 72, 15-21. https://doi.org/10.1016/j.jpsychires.2015.10.010

Meldrum, B. S. (1994). The role of glutamate in epilepsy and other CNS disorders. Neurology, 44(11 Suppl 8), S14-23. Retrieved from http://www.ncbi.nlm.nih.gov/pubmed/7970002

Meme, W., Calvo, C.-F. F., Froger, N., Ezan, P., Amigou, E., Koulakoff, A., ... Giaume, C. (2006). Proinflammatory cytokines released from microglia inhibit gap junctions in astrocytes: potentiation by beta-amyloid. FASEB Journal, 20(1530-6860 (Electronic)), 494-496. https://doi.org/10.1096/fj.05-4297fje

Messing, A., Brenner, M., Feany, M. B., Nedergaard, M., \& Goldman, J. E. (2012). Alexander Disease. Journal of Neuroscience, 32(15), 5017-5023. https://doi.org/10.1523/JNEUROSCI.5384-11.2012

Nagy, J. I., \& Rash, J. E. (2000). Connexins and gap junctions of astrocytes and oligodendrocytes in the CNS. Brain Research. Brain Research Reviews, 32(1), 29-44. Retrieved from http://www.ncbi.nlm.nih.gov/pubmed/10751655

Nikolic, L., Shen, W., Nobili, P., Virenque, A., Ulmann, L., \& Audinat, E. (2018). Blocking TNFa-driven astrocyte purinergic signaling restores normal synaptic activity during 
epileptogenesis. GLIA, 66(12), 2673-2683. https://doi.org/10.1002/glia.23519

Noè, F., Cattalini, A., Vila Verde, D., Alessi, C., Colciaghi, F., Figini, M., ... Curtis, M. (2019). Epileptiform activity contralateral to unilateral hippocampal sclerosis does not cause the expression of brain damage markers. Epilepsia, 60(6), epi.15611. https://doi.org/10.1111/epi.15611

Orkand, R. K., Nicholls, J. G., \& Kuffler, S. W. (1966). Effect of nerve impulses on the membrane potential of glial cells in the central nervous system of amphibia. Journal of Neurophysiology, 29(4), 788-806. https://doi.org/10.1152/jn.1966.29.4.788

Ortinski, P. I., Dong, J., Mungenast, A., Yue, C., Takano, H., Watson, D. J., ... Coulter, D. A. (2010). Selective induction of astrocytic gliosis generates deficits in neuronal inhibition. Nature Neuroscience, 13(5), 584-591. https://doi.org/10.1038/nn.2535

Osei-Owusu, J., Yang, J., Vitery, M. D. C., \& Qiu, Z. (2018). Molecular Biology and Physiology of Volume-Regulated Anion Channel (VRAC). Current Topics in Membranes, 81, 177-203. https://doi.org/10.1016/bs.ctm.2018.07.005

Oya, M., Kitaguchi, T., Yanagihara, Y., Numano, R., Kakeyama, M., Ikematsu, K., \& Tsuboi, T. (2013). Vesicular nucleotide transporter is involved in ATP storage of secretory lysosomes in astrocytes. Biochemical and Biophysical Research Communications, 438(1), 145-151. https://doi.org/10.1016/j.bbrc.2013.07.043

Panatier, A., \& Robitaille, R. (2016). Astrocytic mGluR5 and the tripartite synapse. Neuroscience. https://doi.org/10.1016/j.neuroscience.2015.03.063

Pannasch, U., Vargova, L., Reingruber, J., Ezan, P., Holcman, D., Giaume, C., ... Rouach, N. (2011). Astroglial networks scale synaptic activity and plasticity. Proc.Natl.Acad.Sci.U.S.A, 108(1091-6490 (Electronic)), 8467-8472.

Papadopoulos, M. C., \& Verkman, A. S. (2013). Aquaporin water channels in the nervous system. Nature Reviews. Neuroscience, 14(4), 265-277. https://doi.org/10.1038/nrn3468

Papouin, T., Dunphy, J. M., Tolman, M., Dineley, K. T., \& Haydon, P. G. (2017). Septal Cholinergic Neuromodulation Tunes the Astrocyte-Dependent Gating of Hippocampal NMDA Receptors to Wakefulness. Neuron, 94(4), 840-854.e7. https://doi.org/10.1016/j.neuron.2017.04.021 
1105

1106

1107

1108

1109

1110

1111

1112

1113

1114

1115

1116

1117

1118

1119

1120

1121

1122

1123

1124

1125

1126

1127

1128

1129

1130

1131

1132

1133

1134

Papouin, T., Dunphy, J., Tolman, M., Foley, J. C., \& Haydon, P. G. (2017). Astrocytic control of synaptic function. Philosophical Transactions of the Royal Society B: Biological Sciences, 372(1715), 20160154. https://doi.org/10.1098/rstb.2016.0154

Parri, H. R., Gould, T. M., \& Crunelli, V. (2001). Spontaneous astrocytic Ca2+ oscillations in situ drive NMDAR-mediated neuronal excitation. Nat.Neurosci., 4(1097-6256), 803-812.

Pascual, O., Ben Achour, S., Rostaing, P., Triller, A., \& Bessis, A. (2012). Microglia activation triggers astrocyte-mediated modulation of excitatory neurotransmission. Proceedings of the National Academy of Sciences, 109(4), E197-E205. https://doi.org/10.1073/pnas.1111098109

Pascual, Olivier, Casper, K. B., Kubera, C., Zhang, J., Revilla-Sanchez, R., Sul, J.-Y. Y., ... Haydon, P. G. (2005). Astrocytic Purinergic Signaling Coordinates Synaptic Networks. Science, 310(5745), 113-116. https://doi.org/10.1126/science.1116916

Patel, D. C., Tewari, B. P., Chaunsali, L., \& Sontheimer, H. (2019). Neuron-glia interactions in the pathophysiology of epilepsy. Nature Reviews Neuroscience, 20(5), 282-297. https://doi.org/10.1038/s41583-019-0126-4

Pelegrin, P., \& Surprenant, A. (2006). Pannexin-1 mediates large pore formation and interleukin-1beta release by the ATP-gated P2X7 receptor. EMBO J., 25(0261-4189 (Print)), 5071-5082.

Pellerin, L., Bouzier-Sore, A.-K., Aubert, A., Serres, S., Merle, M., Costalat, R., \& Magistretti, P. J. (2007). Activity-dependent regulation of energy metabolism by astrocytes: An update. Glia, 55(12), 1251-1262. https://doi.org/10.1002/glia.20528

Perea, G, \& Araque, A. (2005). Properties of synaptically evoked astrocyte calcium signal reveal synaptic information processing by astrocytes. Journal of Neuroscience, 25(1529-2401 (Electronic)), 2192-2203.

Perea, G, Navarrete, M., \& Araque, A. (2009). Tripartite synapses: astrocytes process and control synaptic information. Trends Neurosci., 32(1878-108X (Electronic)), 421-431.

Perea, Gertrudis, \& Araque, A. (2007). Astrocytes potentiate transmitter release at single hippocampal synapses. Science, 317(5841), 1083-1086. https://doi.org/10.1126/science.1144640 
1135

1136

1137

1138

1139

1140

1141

1142

1143

1144

1145

1146

1147

1148

Petrelli, F., \& Bezzi, P. (2016). Novel insights into gliotransmitters. Current Opinion in Pharmacology, 26, 138-145. https://doi.org/10.1016/j.coph.2015.11.010

Pirttimaki, T., Parri, H. R., \& Crunelli, V. (2013). Astrocytic GABA transporter GAT-1 dysfunction in experimental absence seizures. The Journal of Physiology, 591(4), 823-833. https://doi.org/10.1113/jphysiol.2012.242016

Ransom, C. B., Ransom, B. R., \& Sontheimer, H. (2000). Activity-dependent extracellular $\mathrm{K}+$ accumulation in rat optic nerve: the role of glial and axonal $\mathrm{Na}+$ pumps. The Journal of Physiology, 522 Pt 3(3), 427-442. https://doi.org/10.1111/j.14697793.2000.00427.x

Rasooli-Nejad, S., Palygin, O., Lalo, U., \& Pankratov, Y. (2014). Cannabinoid receptors contribute to astroglial $\mathrm{Ca}^{2+}$-signalling and control of synaptic plasticity in the neocortex. Philosophical Transactions of the Royal Society B: Biological Sciences, 369(1654), 20140077. https://doi.org/10.1098/rstb.2014.0077

Rassendren, F., \& Audinat, E. (2016). Purinergic signaling in epilepsy. Journal of Neuroscience Research, 94(9), 781-793. https://doi.org/10.1002/jnr.23770

Reichenbach, N., Delekate, A., Breithausen, B., Keppler, K., Poll, S., Schulte, T., ... Petzold, G. C. (2018). P2Y1 receptor blockade normalizes network dysfunction and cognition in an Alzheimer's disease model. The Journal of Experimental Medicine, 215(6), 1649-1663. https://doi.org/10.1084/jem.20171487

Robel, S., Buckingham, S. C., Boni, J. L., Campbell, S. L., Danbolt, N. C., Riedemann, T., ... Sontheimer, H. (2015). Reactive Astrogliosis Causes the Development of Spontaneous Seizures. Journal of Neuroscience, 35(8), 3330-3345. https://doi.org/10.1523/JNEUROSCI.1574-14.2015

Rodrigues, R. J., Tome, A. R., \& Cunha, R. A. (2015). ATP as a multi-target danger signal in the brain. Front Neurosci., 9(1662-4548 (Print)), 148.

Rossi, D., \& Volterra, A. (2009). Astrocytic dysfunction: Insights on the role in neurodegeneration. Brain Research Bulletin, 80(4-5), 224-232. https://doi.org/10.1016/j.brainresbull.2009.07.012

Rossini, L., Garbelli, R., Gnatkovsky, V., Didato, G., Villani, F., Spreafico, R., ... de Curtis, M. (2017). Seizure activity per se does not induce tissue damage markers in human 

neocortical focal epilepsy. Annals of Neurology. https://doi.org/10.1002/ana.25005

Rusakov, D. A., Bard, L., Stewart, M. G., \& Henneberger, C. (2014). Diversity of astroglial functions alludes to subcellular specialisation. Trends in Neurosciences, 37(4), 228242. https://doi.org/10.1016/j.tins.2014.02.008

Santello, M, Bezzi, P., \& Volterra, A. (2011). TNFalpha controls glutamatergic gliotransmission in the hippocampal dentate gyrus. Neuron, 69(1097-4199 (Electronic)), 988-1001.

Santello, Mirko, Toni, N., \& Volterra, A. (2019). Astrocyte function from information processing to cognition and cognitive impairment. Nature Neuroscience, 22(2), 154166. https://doi.org/10.1038/s41593-018-0325-8

Santiago, M. F., Veliskova, J., Patel, N. K., Lutz, S. E., Caille, D., Charollais, A., ... Scemes, E. (2011). Targeting Pannexin1 Improves Seizure Outcome. PLoS ONE, 6(9), e25178. https://doi.org/10.1371/journal.pone.0025178

Savtchouk, I., \& Volterra, A. (2018). Gliotransmission: Beyond Black-and-White. The Journal of Neuroscience, 38(1), 14-25. https://doi.org/10.1523/JNEUROSCI.001717.2017

Sawada, K., Echigo, N., Juge, N., Miyaji, T., Otsuka, M., Omote, H., ... Moriyama, Y. (2008). Identification of a vesicular nucleotide transporter. Proceedings of the National Academy of Sciences, 105(15), 5683-5686. https://doi.org/10.1073/pnas.0800141105

Scemes, E., Velíšek, L., \& Velíšková, J. (2019). Astrocyte and Neuronal Pannexin1 Contribute Distinctly to Seizures. ASN Neuro, 11, 1759091419833502. https://doi.org/10.1177/1759091419833502

Scheffer, I. E., Berkovic, S., Capovilla, G., Connolly, M. B., French, J., Guilhoto, L., ... Zuberi, S. M. (2017). ILAE classification of the epilepsies: Position paper of the ILAE Commission for Classification and Terminology. Epilepsia, 58(4), 512-521. https://doi.org/10.1111/epi.13709

Schipke, C. G., Boucsein, C., Ohlemeyer, C., Kirchhoff, F., \& Kettenmann, H. (2002). Astrocyte $\mathrm{Ca} 2+$ waves trigger responses in microglial cells in brain slices. Faseb J., 16(2), 255-257. https://doi.org/10.1096/fj.01-0514fje 
1194

1195

1196

1197

1198

1199

1200

1201

1202

1203

1204

1205

1206

1207

1208

1209

1210

1211

1212

1213

1214

1215

1216

1217

1218

1219

1220

1221

1222

1223

Schröder, W., Hinterkeuser, S., Seifert, G., Schramm, J., Jabs, R., Wilkin, G. P., .. Steinhauser, C. (2000). Functional and molecular properties of human astrocytes in acute hippocampal slices obtained from patients with temporal lobe epilepsy. Epilepsia, 41 Suppl 6(0013-9580 (Print)), S181-S184. Retrieved from http://www.ncbi.nlm.nih.gov/pubmed/10999541

Schwartzkroin, P. A., Baraban, S. C., \& Hochman, D. W. (1998). Osmolarity, ionic flux, and changes in brain excitability. Epilepsy Research, 32(1-2), 275-285. Retrieved from http://www.ncbi.nlm.nih.gov/pubmed/9761327

Seifert, G., Hüttmann, K., Binder, D. K., Hartmann, C., Wyczynski, A., Neusch, C., \& Steinhäuser, C. (2009). Analysis of astroglial $K+$ channel expression in the developing hippocampus reveals a predominant role of the Kir4.1 subunit. The Journal of Neuroscience : The Official Journal of the Society for Neuroscience, 29(23), 74747488. https://doi.org/10.1523/JNEUROSCI.3790-08.2009

Shen, W., Nikolic, L., Meunier, C., Pfrieger, F., \& Audinat, E. (2017). An autocrine purinergic signaling controls astrocyte-induced neuronal excitation. Scientific Reports, 7(1), 11280. https://doi.org/10.1038/s41598-017-11793-x

Shinozaki, Y., Shibata, K., Yoshida, K., Shigetomi, E., Gachet, C., Ikenaka, K., ... Koizumi, S. (2017). Transformation of Astrocytes to a Neuroprotective Phenotype by Microglia via P2Y 1 Receptor Downregulation. Cell Reports, 19(6), 1151-1164. https://doi.org/10.1016/j.celrep.2017.04.047

Sofroniew, M. V. (2009). Molecular dissection of reactive astrogliosis and glial scar formation. Trends in Neurosciences, 32(12), 638-647. https://doi.org/10.1016/j.tins.2009.08.002

Steinhauser, C., \& Boison, D. (2012). Special Issue: Astrocytes and Epilepsy. Glia, 60(8).

Steinhäuser, C., Grunnet, M., \& Carmignoto, G. (2016). Crucial role of astrocytes in temporal lobe epilepsy. Neuroscience, 323, 157-169. https://doi.org/10.1016/j.neuroscience.2014.12.047

Strohschein, S., Hüttmann, K., Gabriel, S., Binder, D. K., Heinemann, U., \& Steinhäuser, C. (2011). Impact of aquaporin-4 channels on $\mathrm{K}+$ buffering and gap junction coupling in the hippocampus. Glia, 59(6), 973-980. https://doi.org/10.1002/glia.21169 
Studer, F. E., Fedele, D. E., Marowsky, A., Schwerdel, C., Wernli, K., Vogt, K., .. Boison, D. (2006). Shift of adenosine kinase expression from neurons to astrocytes during postnatal development suggests dual functionality of the enzyme. Neuroscience, 142(1), 125-137. https://doi.org/10.1016/j.neuroscience.2006.06.016

Szokol, K., Heuser, K., Tang, W., Jensen, V., Enger, R., Bedner, P., ... Nagelhus, E. A. (2015). Augmentation of $\mathrm{Ca}(2+)$ signaling in astrocytic endfeet in the latent phase of temporal lobe epilepsy. Front Cell Neurosci., 9(1662-5102 (Electronic)), 49.

Tan, Z., Liu, Y., Xi, W., Lou, H., Zhu, L., Guo, Z., ... Duan, S. (2017). Glia-derived ATP inversely regulates excitability of pyramidal and CCK-positive neurons. Nature Communications, 8, 13772. https://doi.org/10.1038/ncomms 13772

Tanaka, K., Watase, K., Manabe, T., Yamada, K., Watanabe, M., Takahashi, K., ... Wada, K. (1997). Epilepsy and Exacerbation of Brain Injury in Mice Lacking the Glutamate Transporter GLT-1. Science, 276(5319), 1699-1702. https://doi.org/10.1126/science.276.5319.1699

Theodosis, D. T., Poulain, D. A., \& Oliet, S. H. R. (2008). Activity-Dependent Structural and Functional Plasticity of Astrocyte-Neuron Interactions. Physiological Reviews, 88(3), 983-1008. https://doi.org/10.1152/physrev.00036.2007

Thom, M. (2014). Review: Hippocampal sclerosis in epilepsy: a neuropathology review. Neuropathology and Applied Neurobiology, 40(5), 520-543. https://doi.org/10.1111/nan.12150

Tian, G. F., Azmi, H., Takano, T., Xu, Q., Peng, W., Lin, J., .. Nedergaard, M. (2005). An astrocytic basis of epilepsy. Nat.Med., 11(1078-8956 (Print)), 973-981.

Tong, X., Ao, Y., Faas, G. C., Nwaobi, S. E., Xu, J., Haustein, M. D., ... Khakh, B. S. (2014). Astrocyte Kir4.1 ion channel deficits contribute to neuronal dysfunction in Huntington's disease model mice. Nature Neuroscience, 17(5), 694-703. https://doi.org/10.1038/nn.3691

Trevelyan, A. J., Muldoon, S. F., Merricks, E. M., Racca, C., \& Staley, K. J. (2015). The Role of Inhibition in Epileptic Networks. Journal of Clinical Neurophysiology, 32(3), 227-234. https://doi.org/10.1097/WNP.0000000000000160

van der Hel, W. S., Notenboom, R. G. E., Bos, I. W. M., van Rijen, P. C., van Veelen, C. 
W. M., \& de Graan, P. N. E. (2005). Reduced glutamine synthetase in hippocampal areas with neuron loss in temporal lobe epilepsy. Neurology, 64(2), 326-333. https://doi.org/10.1212/01.WNL.0000149636.44660.99

van Vliet, E. A., Aronica, E., \& Gorter, J. A. (2015). Blood-brain barrier dysfunction, seizures and epilepsy. Seminars in Cell \& Developmental Biology, 38, 26-34. https://doi.org/10.1016/j.semcdb.2014.10.003

van Vliet, E. A., Aronica, E., Vezzani, A., \& Ravizza, T. (2018). Review: Neuroinflammatory pathways as treatment targets and biomarker candidates in epilepsy: emerging evidence from preclinical and clinical studies. Neuropathology and Applied Neurobiology, 44(1), 91-111. https://doi.org/10.1111/nan.12444

Verderio, C., Cagnoli, C., Bergami, M., Francolini, M., Schenk, U., Colombo, A., ... Matteoli, M. (2012). TI-VAMP/VAMP7 is the SNARE of secretory lysosomes contributing to ATP secretion from astrocytes. Biology of the Cell, 104(4), 213-228. https://doi.org/10.1111/boc.201100070

Verkhratsky, A., Matteoli, M., Parpura, V., Mothet, J.-P., \& Zorec, R. (2016). Astrocytes as secretory cells of the central nervous system: idiosyncrasies of vesicular secretion. The EMBO Journal, 35(3), 239-257. https://doi.org/10.15252/embj.201592705

Verkhratsky, Alexei, \& Parpura, V. (2016). Astrogliopathology in neurological, neurodevelopmental and psychiatric disorders. Neurobiology of Disease, 85, 254261. https://doi.org/10.1016/j.nbd.2015.03.025

Vesce, S., Rossi, D., Brambilla, L., \& Volterra, A. (2007). Glutamate release from astrocytes in physiological conditions and in neurodegenerative disorders characterized by neuroinflammation. Int.Rev.Neurobiol., 82(07), 57-71. https://doi.org/10.1016/S0074-7742(07)82003-4

Vezzani, A., French, J., Bartfai, T., \& Baram, T. Z. (2011). The role of inflammation in epilepsy. Nat.Rev.Neurol., 7(1759-4766 (Electronic)), 31-40. https://doi.org/10.1038/nrneurol.2010.178

Volterra, A., Liaudet, N., \& Savtchouk, I. (2014). Astrocyte Ca2+ signalling: an unexpected complexity. Nature Reviews Neuroscience, 15(5), 327-335. https://doi.org/10.1038/nrn3725 
Wallraff, A., Kohling, R., Heinemann, U., Theis, M., Willecke, K., \& Steinhauser, C. (2006). The impact of astrocytic gap junctional coupling on potassium buffering in the hippocampus. J Neurosci., 26(1529-2401 (Electronic)), 5438-5447.

Walz, W. (2000). Role of astrocytes in the clearance of excess extracellular potassium. Neurochemistry International, 36(4-5), 291-300. Retrieved from http://www.ncbi.nlm.nih.gov/pubmed/10732996

Wang, Y., Zaveri, H. P., Lee, T.-S. W., \& Eid, T. (2009). The development of recurrent seizures after continuous intrahippocampal infusion of methionine sulfoximine in rats: a video-intracranial electroencephalographic study. Experimental Neurology, 220(2), 293-302. https://doi.org/10.1016/j.expneurol.2009.08.034

Wellmann, M., Álvarez-Ferradas, C., Maturana, C. J., Sáez, J. C., \& Bonansco, C. (2018). Astroglial Ca2+-Dependent Hyperexcitability Requires P2Y1 Purinergic Receptors and Pannexin-1 Channel Activation in a Chronic Model of Epilepsy. Frontiers in Cellular Neuroscience, 12, 446. https://doi.org/10.3389/fncel.2018.00446

Wilcock, D. M., Vitek, M. P., \& Colton, C. A. (2009). Vascular amyloid alters astrocytic water and potassium channels in mouse models and humans with Alzheimer's disease. Neuroscience, 159(3), 1055-1069. https://doi.org/10.1016/j.neuroscience.2009.01.023

Xiong, Y., Sun, S., Teng, S., Jin, M., \& Zhou, Z. (2018). Ca2+-Dependent and Ca2+Independent ATP Release in Astrocytes. Frontiers in Molecular Neuroscience, 11, 224. https://doi.org/10.3389/fnmol.2018.00224

Zamanian, J. L., Xu, L., Foo, L. C., Nouri, N., Zhou, L., Giffard, R. G., \& Barres, B. A. (2012). Genomic Analysis of Reactive Astrogliosis. Journal of Neuroscience, 32(18), 6391-6410. https://doi.org/10.1523/JNEUROSCI.6221-11.2012

Zhang, Z., Chen, G., Zhou, W., Song, A., Xu, T., Luo, Q., ... Duan, S. (2007). Regulated ATP release from astrocytes through lysosome exocytosis. Nature Cell Biology, 9(8), 945-953. https://doi.org/10.1038/ncb1620

Zhao, B., Gu, L., Liu, K., Zhang, M., \& Liu, H. (2017). Maxi-anion channels play a key role in glutamate-induced ATP release from mouse astrocytes in primary culture. NeuroReport, 28(7), 380-385. https://doi.org/10.1097/WNR.0000000000000759 
1314 Zhao, Z., Nelson, A. R., Betsholtz, C., \& Zlokovic, B. V. (2015). Establishment and Dysfunction of the Blood-Brain Barrier. Cell, 163(5), 1064-1078. https://doi.org/10.1016/j.cell.2015.10.067

1317 Zimmermann, H. (1994). Signalling via ATP in the nervous system. Trends in $1318 \quad$ Neurosciences, 17(10), 420-426. Retrieved from

1319 http://www.ncbi.nlm.nih.gov/pubmed/7530880

1320 
1322 